Hamood Ur Rehman $₫$

Ferenc Boór

Muhammad Wasif

Syed Amir Iqbal

https://doi.org/10.21278/TOF.454027821

ISSN 1333-1124

eISSN 1849-1391

\title{
A NOVEL METHOD FOR PROCESS PLANNING FOR DIE AND MOULD MANUFACTURING USING EXPERT SYSTEM APPROACH
}

\begin{abstract}
Summary
Mould design and development are experience-oriented operations involving complex process planning integration and relatively time-consuming processes. A solution for integrating the process planning with manufacturing operations for mould design and development is presented. In this paper, the developed solution is related to cost and time. The main aim of the study is to optimize the whole process planning scenario and make it feasible and accessible for faster and optimum design to manufacture die and moulds for injection moulding applications. The developed method consists of group technology (GT) coding for part and tool linked to the manufacturing process and its criticalities. An impact factor rating system is established using the weighted average method to associate the manufacturing operations with time and cost combined with the matrix reduction method so as to produce an optimized sequence of operations. The effect of restricting certain criticalities (electric discharge machine usage, quality and complexity) on the GT code is also elaborated in reference to quality and other parameters. The resultant study presents a novel method of establishing an expert system (ES) that combines GT coding, manufacturing operations, weighted average and matrix reduction to optimize the process planning. The rationale behind the research is an effective use of the ES in optimizing process planning applications in digital manufacturing.
\end{abstract}

Key words: $\quad$ process planning, expert system, tool design, injection mould, group technology, digital manufacturing

\section{Introduction}

It is requirement of industry to produce tooling with shorter lead times and desired robustness due to the fierce competition, short product life cycles, rapid technological advancements, and fast paced markets. This requirement triggers the need for optimal process design and low cost of quality to meet the requirements of feasibility and market demand. After designing a product, process planning is one of the challenging tasks of the manufacturing industry, where multiple solutions are available to produce a single part with their own pros and cons. In process planning, a single person or a team is hired to transform the product design into different manufacturing processes so as to streamline the manufacturing system and convert the raw material into the designed product [1]. 
Expert Systems (ES) are being implemented almost in all kinds of decision making, such as forecasting, product development, process planning, strategic planning, etc. These systems are based on expert's decision, which is based on the knowledge learnt from experience that resulted in successful outcomes. In other words, these knowledge-based practices are the best practices but in the form of data rather than descriptions or books which are fed into a database of a system to extract results based on a given situation [2].

Dies and moulds are basic tools used in most manufacturing processes to produce components of automobiles, consumer products, electronic items and aircraft. The production of industrial goods requires manufacturing of discrete parts that are assembled to finished products. Forging, moulding and other manufacturing processes used to produce large quantities of parts require dies and moulds. Design, development and try-out of new dies and moulds may be critical in determining the feasibility and lead-times of an entire research and development (R\&D) programme. The quality of dies and moulds directly affects the cost of quality of the production. The use of ESs to aid the process planning of dies and moulds design and manufacture may positively affect the development process, resulting in favourable feasibility, low cost of quality and decreased lead time [2].

The core objective of this study is to shorten the process planning of product manufacture using an ES. Therefore, a unique process planning technique is used incorporating the existing framework of a part, recognizing the need for the tool, and identifying and sequencing the manufacturing processes. A comprehensive literature review has been carried out to define the scope of research. The literature review can be divided into three main segments: machining of dies and moulds, use of ESs in computer-aided process planning (CAPP) and automated CAPP using other techniques.

\subsection{Machining of dies and moulds}

De Lacalle et al. focused on the process planning for machining of die and mould using computer-aided manufacturing (CAM) systems. They proposed a CAM system which is responsible for numeric control (NC) programs used for parts to be moulded and to make it compatible with high-speed milling (HSM) operations. Software packages such as Vericut and Catia are integrated with optimizing parameters to facilitate the process [3]. Lim et al. presented a tool path planning method and integrated an ES to maximize the productivity using higher feed rates of materials. This includes a database of materials and allowable ranges of process parameters which can be used to maximize the yield of production [4]. Wang and Chen used $\mathrm{CAD}, \mathrm{CAM}$ and CAE integration to optimize the design of tool manufacturing for minimum deflection. This method drastically improves the accuracy of the machining resulting in precise moulds with accurate dimensions [5]. Krajnik et al. presented a comparison between the application of traditional and high-speed machining over the manufacturing of dies and moulds [6]. Le et al. proposed that one way to reuse old moulds and dies in its essence is to use hybrid manufacturing, which involves additional manufacturing with the principles of end-of-life (EOL) manufacturing. This method overrode restrictions on additional fabrication such as surface weakness, dimensional inaccuracy, material availability and long cycle times. The method primarily used in this approach usually involves direct energy deposition (DED) such as direct material deposition (DMD) and other powder bed fusion (PBM) techniques such as selective laser machining (SLM) and electron beam melting (EBM) [7]. Atlan et al. focused on the process planning of tool die designing and manufacturing with geometrical planning. However, such process planning does not consider the criticalities of the HSM process. The authors also worked on the optimization of the $\mathrm{NC}$ code for feed rates to achieve faster production. An approach was developed to utilize G-OPTIM (a developed program) to convert the provided feed rate to subcategories, such as the curve feed rate, sharp direction feed rate, direct numeric control (DNC) feed rate and cycle feed rate, and to optimize the machining performance accordingly [8]. 


\subsection{Expert systems in computer-aided process planning (CAPP)}

Martinez et al. presented an integer-based optimization of process planning for the pulp packaging industry. They developed a simple algorithm to select a suitable mould for the production based on the demand and the lead time [9]. Wu and Wang proposed a study to map thinking and imprecision of the human mind for planning a neuro-fuzzy approach. The developed neuro-fuzzy system worked by building rules, i.e. IF-THEN and IF-ELSE, and assigning weights and priorities to each rule, after some complicated assessment produced a de-fuzzified output. To create a successful neuro-fuzzy system, a decision and knowledge-based ES was required which may even not be accurate all the time because of imprecision in the human decision context [10]. Cakir et al. developed a new ES incorporating the issues of clamping methods, type of milling operation, feed direction of the cutting tool, etc. They also included the important requirements of any process planner regarding the die and mould, such as the surface being machined, workpiece material, type of application and tool material. This ES provides outputs such as available tool type, work holding method to be employed, direction of feed (up/down milling), method of machining, depth of cut, offset values and other miscellaneous information [11]. Lim et al. proposed to use a CLIPS (C Language Integrated Production System) ES tool which uses the manufacturing part recognition combined with the part feature database to give a potential production plan for the required die and mould production [12]. Nakao et al. proposed a set of standards in the sequence of operations, fixing parameters for operations which are based on the item group most often produced in the industry, deleting dependent decisions from the human and just deciding on primary variables, combining pre-operations to converge to a faster decision and reducing the number of selection options and parallel processes [13].

Wongwiwat et al. studied production scheduling for injection moulding manufacture using the Petri net (PN) model. In their study they established that in the injection moulding process the mould and die manufacturing is governed by the lowest makespan cut (LMC) which was a contributing factor derived from the lowest makespan (LM). An effective method to reduce the time of die and mould manufacturing was necessary [14]. Miko et al. worked on the cost and time estimation of the dies and mould manufacturing for a quotation. They made an analytical model which estimated the cost based on the part complexity and quality [15]. Denkena and Nemeti proposed a model to predict a realistic price of dies and mould manufacturing for quotation purposes. It was suggested that accurate price estimation was directly related to quality and complexity in calculations but many times this was replaced by estimates based on past experience. For better price estimates high co-ordination at a crossfunctional level was needed within a company especially in the tool design areas [16]. Vázquez et al. studied micro milling of mould cavities for ultrasonic moulding applications and developed a certain process planning algorithm clearly highlighting workpiece, tool and process requirements and deriving tool and process parameters from the input [17].

\subsection{Automated computer-aided process planning (CAPP)}

Kumar presented the use of artificial intelligence in the computer-aided process planning (CAPP). He divided his review into three basic fields of CAPP: i) feature-based design and modelling, which is the main input to the CAPP system, ii) ESs and their applications and iii) state-of-the-art evolutionary techniques, which are being implemented in the CAPP [18]. Chen et al. presented advancements in dies and moulds manufacturing including the latest techniques of CAD, CAM, CAPP and CAE [19]. Basinger et al. proposed a modular based CAPP approach for hybrid manufacturing focusing on the additive-subtractive approach and limiting the study to pocket holes and flat surfaces [20]. Wswase et al. presented an automated CAPP research integrating the CAD and CAM technique. They highlighted that the automatic feature recognition (AFR) technique is an efficient technique for the automated CAPP [21]. Behandish et al. established an automated CAPP using the additive and subtractive techniques on parts. They used 
the finite Boolean algebra (FBA) technique to define forming codes for the product. They claimed that the process was robust since it used logical searching and FBA techniques [22]. Karim et al. presented a simplified CAPP technique, which read the data file of the part and tool, and based on the geometrical definition it decided which manufacturing process and tooling are appropriate. A sample problem is also used as the application of the study problem [23].

\subsection{Development of CAPP system for mould manufacturing}

In most of the studies presented above, the CAPP approach was developed, limited to the part, die, moulds and operations. Especially the ESs used in these studies are limited to the number of operations and complexity of geometry. Contributing to the field of process planning, a new method has been developed. This process planning system comprises the use of an existing part identification system based on group technology and the development of tool attributes for dies and moulds based on group technology, combined to form an ES. Part complexity and quality are also attributed to the tool as provided by the customer. The sequence of manufacturing processes is optimized using the ES. Finally, based on the complexity, the quality, the manufacturing process and tooling requirements, cost and time analyses are also performed.

The pyramid (Fig. 1) deals with the gist of the developed algorithm and expands on how general part design characteristics can be incorporated in the decision-making process. The part design attributes contain external and internal features of the part, part class complexity and other design features that are directly related to the tool being manufactured for the production of a part. The higher hierarchy deals with the manufacturing tool attributes directly derived from the part attributes, where a relational linkage is established impacting the change of design attribute to part attribute. On the basis of the manufacturing attributes the process planning for the mould (tool production) is carried out, which defines the manufacturing operations to be employed, the sequence of operations to be carried out and criticalities of the manufacturing operation. As a result of the achieved process planning outcome a quantifiable factor for the time and cost impact rating can be obtained, which helps in decision making. The pyramid shows the approach to the whole algorithm providing details about the integration of the decision making with design attributes and process planning in the mould tool manufacturing. These attributes and process planning come together to aid the decision making for the mould tool manufacture.

The paper has five sections: section 1 presents the research problem and literature review. Section 2 deals with the methodology of the research. Section 3 describes the developed algorithm for process planning. Then, section 4 explains the application and provides an example and section 5 concludes the study.

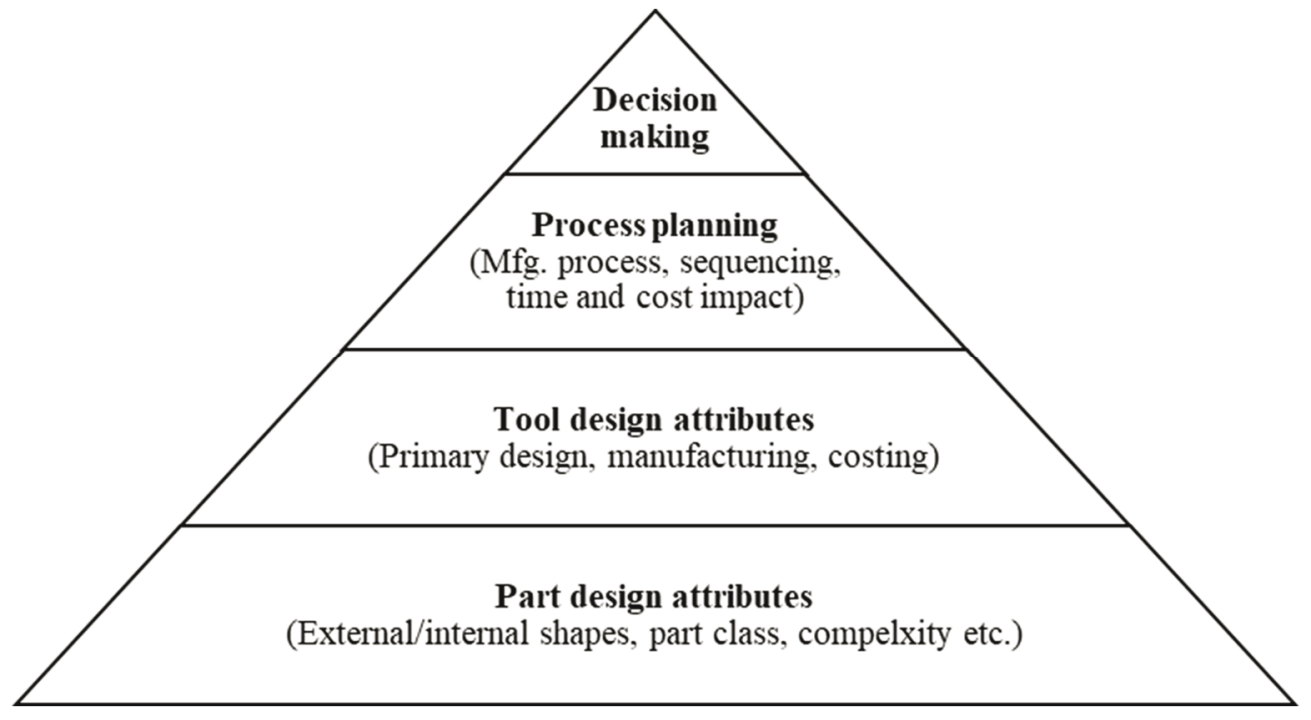

Fig. 1 Pyramid approach to decision making in the planning of mould manufacturing process 


\section{Methodology}

The main issue in the current trend in manufacturing is that major manufacturing capabilities are still experience-oriented which lengthens the time for production planning and results in an incorrect prediction of time and costs. This study addresses these issues by optimizing and automating the manufacturing processes.

A detailed study of part design attributes (feature based) is carried out along with their related effect on tooling. The work involves studying the dies, moulds and related manufacturing criticalities along with their dependencies on the part design attributes and their effect on the manufacturing attributes of the tool. This led to the development of a part identification system that incorporates design attributes of dies and moulds. The development of a manufacturing-based coding system and correlating it with the design attribute of a part as well as setting up a manufacturing process database that changes its characteristics with the changing attributes of part and tool are accomplished as part of the next phase.

The developed coding system integrates a detailed study of criticalities that should be considered for each process during the selection. The impact of the selected manufacturing processes is related to the time and costs of manufacturing. An output is generated displaying the impact of criticalities of the manufacturing processes on the time and cost impact rating. Manufacturing restrictions are also incorporated in the code by sustaining a certain preset requirement from the customer or manufacturer (effect of prerequisites on the coding system) which is combined with an associated method for automatic selection of an optimum sequence of operations and linking it to the developed code. The system resulting from the study is the so-called ES that provides ease in the decision making and planning of the part in a shorter and more productive way. Figure 2 elaborates the direction of the research, where each component can be further defined as follows:

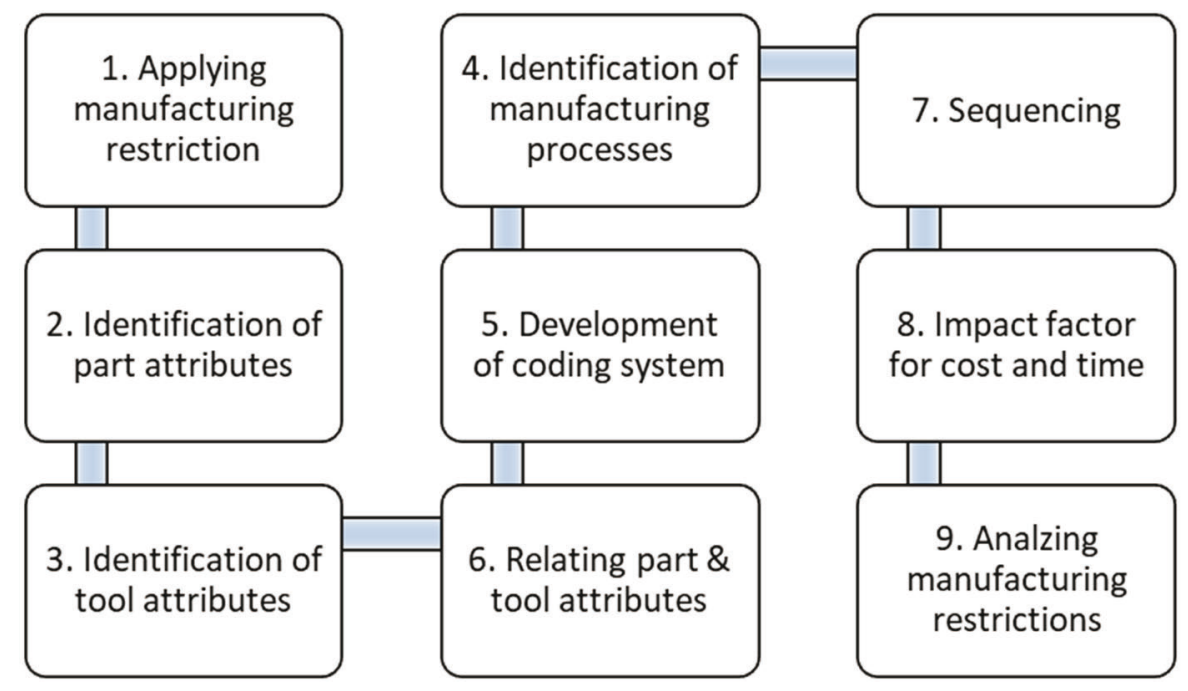

Fig. 2 Illustration of methodology

Applying Manufacturing Restrictions: Restrictions are defined in the system where certain established restrictions (EDM usage, complexity, quality, time) are imposed, which in turn restricted the values in the GT code thereby restricting also the manufacturing process, time and cost ratings.

Identification of Part: This part of the study is concerned with the identification of design aspects of the part to be manufactured. The Opitz code is taken as reference to include the features of the part which may serve as input to drive the whole algorithm [24].

Identification of Tool Attributes: It deals with relating the design parameters of the part with the manufacturing attributes of the tool that would be used to manufacture the part. A 
group technology (GT) code is developed in this study, uniquely for such problems, including all the parameters inherent in the tool that affect the manufacturing processing, time and cost requirements.

Relating Part and Tool Attributes: Geometrical attributes of the part and the tool are related to each other. The relation is done in such a manner that changing or fixing one attribute will have a direct impact on other attributes.

Development of Coding System: This part is concerned with combining the GT codes into one and ascertaining that both work well with one other. Here, a restriction analysis of relating each code is also carried out and the effect of restricting one parameter in the whole system is also justified.

Identification of Manufacturing Processes: The manufacturing processes are identified in this part of the study based on the codes developed earlier. Each code assigned in the previous step relates one or multiple manufacturing processes to produce a desired feature. Each process having different value in the GT code is accompanied by a certain set of criticalities which are identified to have a significant impact during manufacturing and must be taken into account during machining. The process is setup in such a manner that triggering a set of values in the GT code will enable the manufacturing processes as well as the process criticalities to be considered during machining.

Sequencing: The developed GT code system is linked to sequencing the operations derived from the matrix reduction technique. It is to be noted that the predecessor of each process will be provided by the process planner since the system cannot recognize the mandatory predecessor of the manufacturing processes.

Analyzing Manufacturing Restrictions: Here, the restrictions of the manufacturing processes are analyzed. Higher complexity and high quality directly impact the cost, the dies and the mould completion time is increased as a function of increase in complexity and quality. In this step, the provided restrictions (EDM usage, complexity, quality, time) are reviewed, and based on the customer requirements the finalized restrictions which affect the GT code are imposed.

Impact factor for Cost and Time: A mathematical algorithm is developed relating the GT code, manufacturing processes and criticalities. The relationships of these aspects with the cost and time are developed so that the assessment of the cost and time can be performed, which can be manipulated by simplifying the criticalities. The impact factor calculated using this algorithm can be used to quote the time and cost of manufacturing dies and moulds in the industry.

After developing the algorithm, one sample part is processed through the algorithm. An application example is taken to verify the robustness of the developed algorithm, which is presented in section 4 .

\section{ES algorithm}

In line with the approach, an integrated system is developed that relates part, tool manufacturing and design attributes. The relationship is developed and coded in the way described in the following section. This GT code consists of 23 digits, including the part identification codes, tool attribute identification and other manufacturing criticalities. The coding system bases its structure on the hybrid structure type configuration, the combination of chain and the hierarchal structure configurations. Based on the manufacturing criticalities, this combined factor is utilized to produce a list of possible manufacturing processes and specifically the sequence that will be followed. That sequence and operations are used to determine the cost and time impact as well as the criticalities of each process to be considered. The overall algorithm of the process planning is shown in Fig. 3. An elaborative ES framework is shown in Fig. 4. 
This ES is referred to as Mould Tool ES or simply MTES. The details of each process developed in the algorithm are as follows.

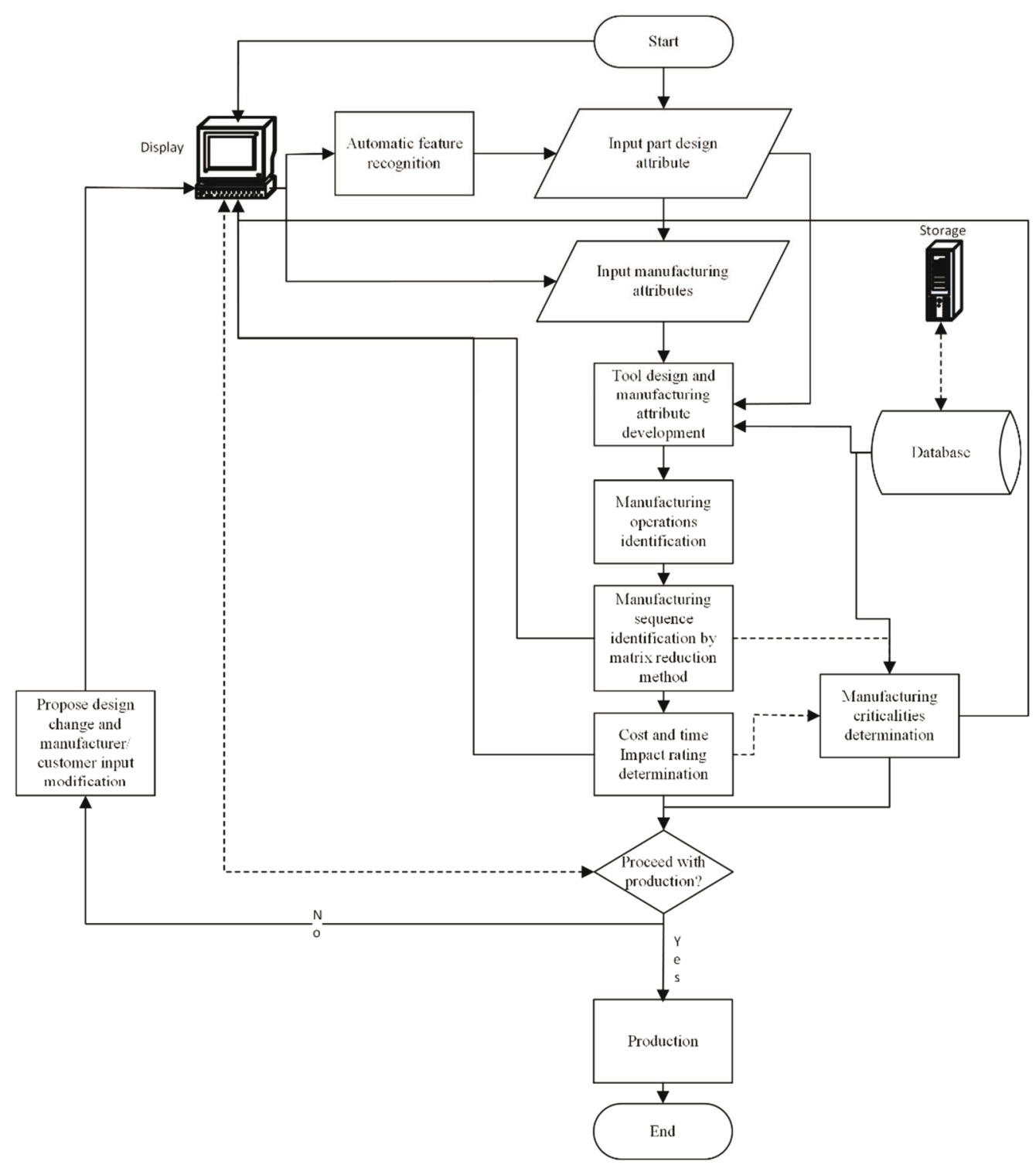

Fig. 3 Overview of the developed algorithm showing the process planning from start to finish

The developed algorithm takes input from the part design attributes (see Fig. 4) by applying the AFR technique such as graph-based to hint-based algorithm or the Rete algorithm (CLIPS etc.), which may be applied to serve as an information input in order to identify part class, complexity, internal/external shape element, plane surface finish requirement, auxiliary hole and gear tooth requirement. The identified part design attributes will serve as a means for defining tool design and manufacturing attributes.

The determined tool design manufacturing attributes will result in a particular sequence of manufacturing operations and based on the manufacturing operations and the time-oriented restriction scenario a particular sequence of operations will be selected by processing the inputs applying the matrix reduction technique. This determined sequence will give a time and cost impact rating which may be utilized to make a particular decision with regards to production. By selecting a time and cost impact rating as well as a sequence of operation a particular list of manufacturing criticalities may be created in form of a manufacturing report. 


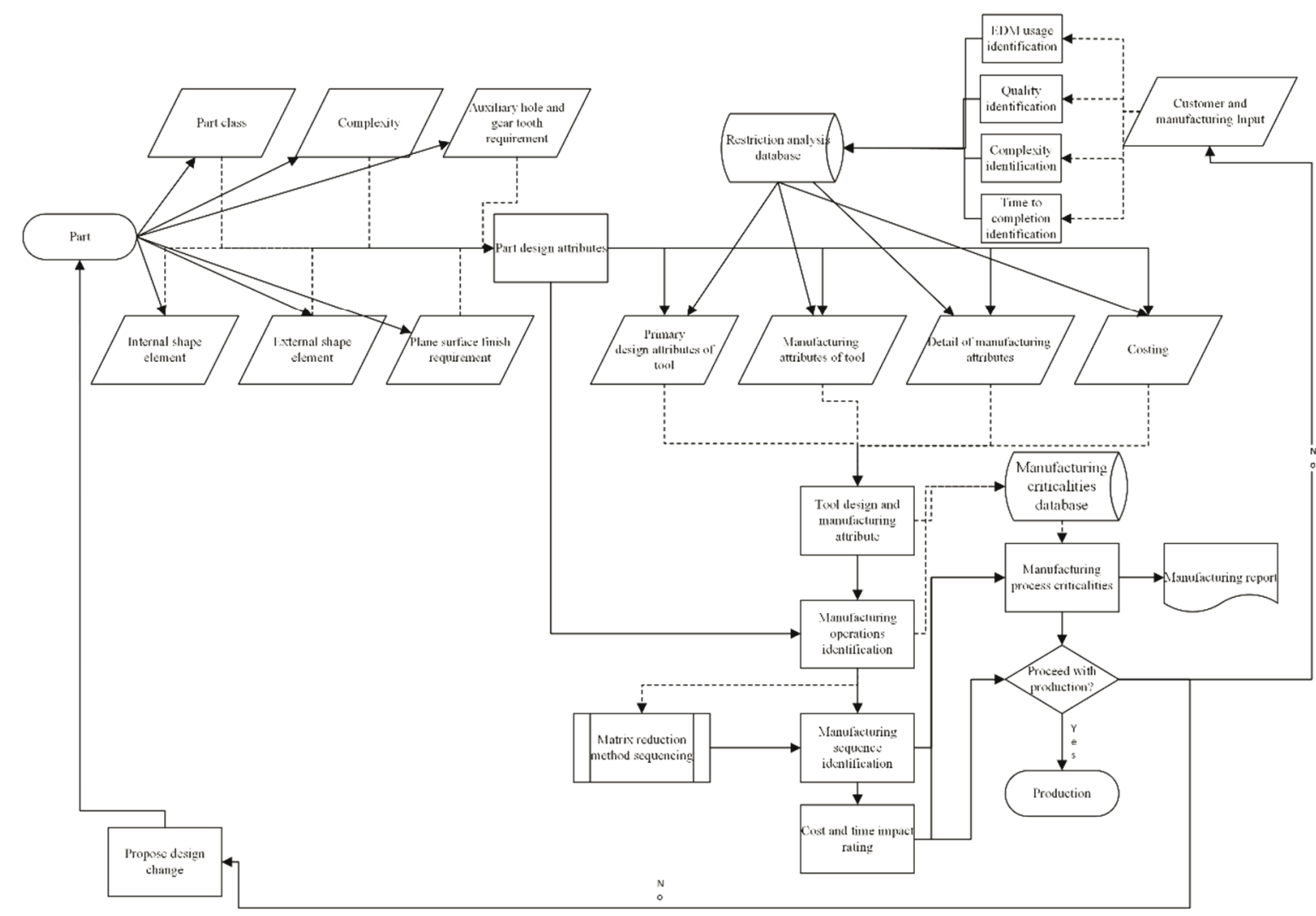

Fig. 4 Elaborative framework of the algorithm linking part and tool attributes with process planning from start to finish

The whole process is iterative in nature, i.e. if in some case the decision does not support the production requirements (plan, equipment or any other), then a change in the design of the part may be suggested and a change in the manufacturing and customer-based restrictions may be taken into account.

\subsection{Manufacturing restrictions}

While giving suggestions, the ES considers the manufacturing restrictions. The developed restrictions encompass low, medium and high usage of EDM and low, medium and high quality and complexity, whereas for the time aspect the mode can be fast or normal. These aspects will be defined by the customer or manufacturer based on consultation, costs, process requirements, delivery, availability, etc. When imposed, these restrictions will place certain limitations on the GT code, which in turn affects the time and cost impact rating. A major component that can affect equipment availability, sequencing, cost and tolerance of the produced part is the EDM usage. If a restriction of high, medium or low usage of EDM is imposed by the manufacturer/customer, this will result in certain restrictions on the selection of certain components of the GT code, thereby limiting the sequence and operation selection. Table 1 presents the manufacturing restrictions which can be applied in this system. Each of the manufacturing restriction corresponds to a change in the tool GT code, which will be defined in the following sections.

Table 1 Manufacturing restriction conditions and considerations

\begin{tabular}{|l|l|l|}
\hline Code & Feature & Description \\
\hline \multirow{3}{*}{$\begin{array}{l}\text { Use } \\
\text { EDM }\end{array}$} & Low & Up to $20 \%$ of mould cavity \\
\cline { 2 - 3 } & Moderate & Up to $50 \%$ of mould cavity \\
\cline { 2 - 3 } & High & Up to $80 \%$ of mould cavity \\
\hline
\end{tabular}




\begin{tabular}{|c|c|c|}
\hline Code & Feature & Description \\
\hline \multirow{2}{*}{$\begin{array}{l}\text { Time of } \\
\text { completion }\end{array}$} & Normal & Schedule based on the cycle time of processes \\
\hline & Fast & Fast track schedule eliminating details \\
\hline \multirow{3}{*}{$\begin{array}{l}\text { Quality of } \\
\text { dies and } \\
\text { moulds }\end{array}$} & High & $\begin{array}{l}\text { All components of dies and moulds must follow } \\
\text { current standards }\end{array}$ \\
\hline & Medium & $\begin{array}{l}\text { Up to } 50 \% \text { components must follow current } \\
\text { standards }\end{array}$ \\
\hline & Low & $\begin{array}{l}\text { Mould can be designed optimally by } \\
\text { implementing only the needed standard }\end{array}$ \\
\hline \multirow{3}{*}{ Complexity } & High & Fine details along with a number of cavities \\
\hline & Medium & Intricate details with a single cavity \\
\hline & Low & Fewer details with a single cavity \\
\hline
\end{tabular}

\subsection{Part identification}

The developed algorithm takes input from the part design attributes such as part class, complexity, internal/external shape element, plane surface finish requirement, auxiliary hole and gear tooth requirement. The first six digits of the developed codes refer to the part attributes derived from the Opitz system developed by RWTH Aachen [24]. Table 2 illustrates the details of the six-digit code for the part identification.

Table 2 Form code (Opitz system) for the part identification

\begin{tabular}{|c|c|c|c|}
\hline $\begin{array}{l}\text { Code } \\
\text { Position }\end{array}$ & $\begin{array}{l}\text { Code } \\
\text { Name }\end{array}$ & Feature & Description \\
\hline 0 & $\mathrm{P}_{1}$ & Part class & $\begin{array}{l}\text { Based on the rotational and non-rotational } \\
\text { characteristics of the part. For identification of } \\
\text { turning operation. }\end{array}$ \\
\hline 1 & $\mathrm{P}_{2}$ & External shape element & Various types based on external periphery. \\
\hline 2 & $\mathrm{P}_{3}$ & Internal shape element & $\begin{array}{l}\text { This digit implies the internal shape feature of } \\
\text { rotational parts and general rotational shape } \\
\text { features of non-rotational parts. }\end{array}$ \\
\hline 3 & $\mathrm{P}_{4}$ & Plane surface machining & Flats, slots etc. \\
\hline 4 & $\mathrm{P}_{5}$ & $\begin{array}{l}\text { Auxiliary holes and } \\
\text { gear teeth }\end{array}$ & Based on external machining. \\
\hline 5 & $\mathrm{P}_{6}$ & Complexity & $\begin{array}{l}\text { This digit implies visual experience-based } \\
\text { characteristic quotation of the part on how it } \\
\text { is perceived in terms of complexity of } \\
\text { manufacture. }\end{array}$ \\
\hline
\end{tabular}

\subsection{Identification of tool attributes}

The identified part design attributes will serve to define the tool design and manufacturing attributes. A system of tool design code has been introduced in this study. Based on group technology (GT), these codes are developed starting from $\mathrm{P}_{7}$ to $\mathrm{P}_{23}$. Here, a multiple chain type structure coding is developed and linked together for the manufacturing process and sequence identification, hence a new type of a hybrid structure coding system is generated. The tool design and manufacturing attributes are divided into the primary design attribute, the manufacturing attribute, the associated manufacturing detail and costing. These attribute details are shown in Fig. 5. 


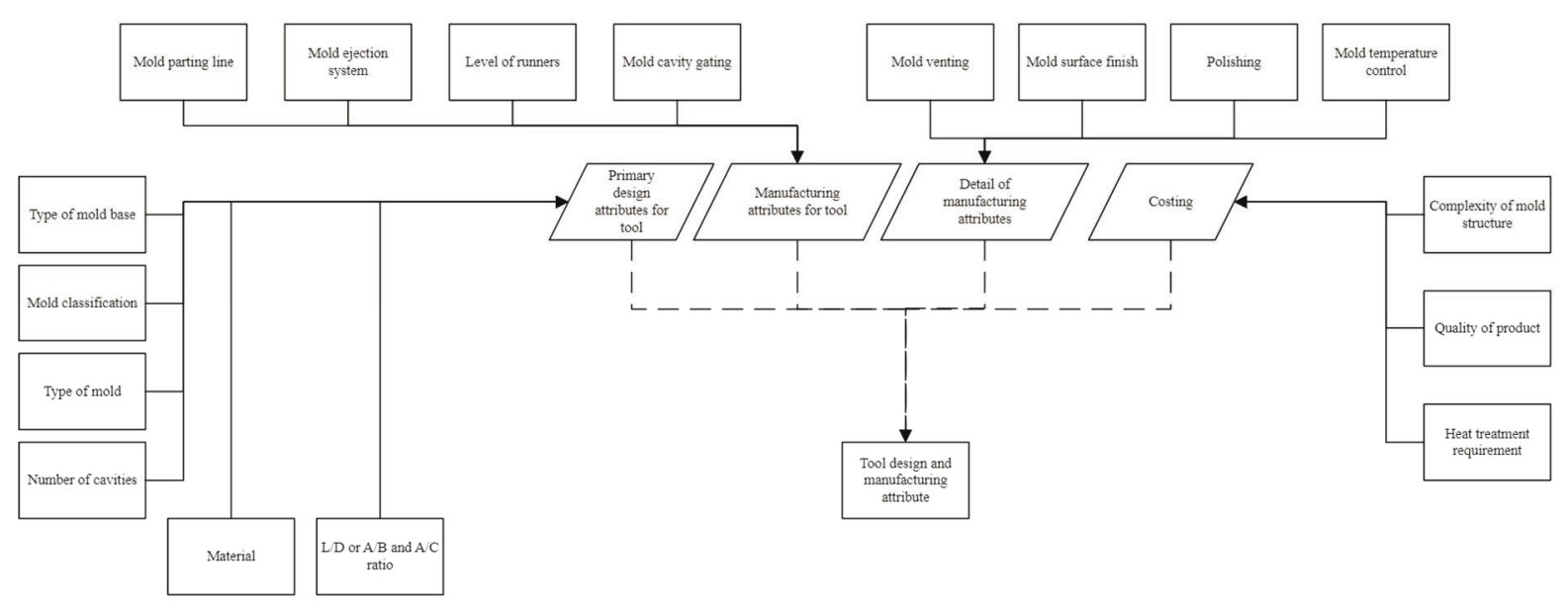

Fig. 5 Detail of tool design and manufacturing attributes

The primary design attribute is composed of those components that affect the manufacturing of the tool. Since the mould consists of a cavity that can be simply considered to be the negative of the part being produced, the $\mathrm{L} / \mathrm{D}$ (rotational), $\mathrm{A} / \mathrm{B}$ or $\mathrm{A} / \mathrm{C}$ (non-rotational) ratio which is derived from the part class attribute can be supplemented to be the same as in the case of a mould. Material needed to produce a mould is an important consideration that affects the manufacturing planning, operations and costing attributes, directly influencing the part being moulded. Hence the material is considered. The factor that influences the manufacturing of the mould tool significantly is the number of cavities involved in the mould needed to produce the parts. Therefore, the number of mould cavities is integrated into the GT code in such a manner that increasing the mould cavities increases the costing component of the GT code. Other significant parameters that are considered are type of mould, mould base and mould classification. These components are based on the quantity of the parts and the process requirement for the machine as the mould base orientation can be divided according to machine feasibility into rectangular and round cross-sections. Depending on the volume the moulds can be classified into prototype, production and high-volume moulds, which in turn would affect all other GT code components including the material through to costing. The moulds on the other hand can be further classified into the mould design which influences manufacturing; for instance, the choice of having a two-plate mould or a three-plate mould will have different requirements. If instead of a cold-runner system, a hot-runner capability is selected, then this change adds to the manufacturing conditions influencing mould manufacture.

The manufacturing attributes of the tool deal with those aspects that will greatly affect the manufacturing requirements as compared to the primary design attributes that cover the design related characteristics of the tool produced. The parting line can be straight, stepped, profiled and tapered, each with a specific machining requirement. The selection of an ejection system that will be employed will have a separate machining requirement, such as ejector pin, stripper plate, ejection sleeve, etc. and will involve different design and manufacturing considerations. How a runner system (round or trapezoidal) is divided into sub-runner levels (single sub-runner to multiple level) will be an important consideration as it would define the milling requirement and will be influenced by the number of cavities to be filled in a single shot cycle. Along with this the cold and hot runner systems will have different machining requirements. If hot runner systems are selected, the tool cost increases as the machining cost increases, however this change shows better repeatability and lower overhead costs. Cold runners are mostly suitable for smaller quantity production and fast testing attributed to shorter setup costs and higher flexibility. Selection of the gating requirement for the tool is also quite critical as it would influence weld lines, flow lines, flow distribution and stress accumulation in the part. Different gating would have different manufacturing requirements and once the part 
is produced from such gates, a gate scar is left when gate is removed, which would depend on part topology, feature requirement and cosmetics. These components of the GT code will have great influence on manufacturing variations between mould tool designs.

The next component of the GT code goes further into more detail regarding the manufacturing aspects. The number of cavities, type of gating, runner system and material to be used for injection moulding will define the size of the required vent. Moreover, the mould surface finish defines the overall finish of the part being produced. The mould forming method and the polishing method used have great influence in this regard. Once the part is produced, it must be ejected from the mould, therefore it is to be cooled first. Temperature management in the mould can be carried out by using water or a water/ethylene glycol mixture. Here, the main concern is the presence of a chilling unit and the capability of the auxiliary temperature control unit to accommodate the coolant. The coolant channel pattern can also play a key role in the machining considerations. The selection may be based on the simple, simple level (plug inlet outlet concept) and multi-level cooling circuit. The core cooling circuit and the cooling circuit for cavity inserts may also play a role. A standard in this regard should be taken into the account. Heating media such as hot water, steam heat and hot oil can be utilized in the temperature control mechanism for the mould-heating and mould-cooling phases depending upon the material and heating requirements of the part being made.

The costing attribute builds on the primary design and manufacturing attributes. The costing is based on the selection of heat treatment requirements, complexity of the mould structure and quality of the product produced. The method of heat treatment selection is based on distortion in heat treatment (shape and size distortion), safety and depth of hardening on mould steel and resistance to decarburization. The complexity and quality depend on the manufacturer/customer input (design and manufacturing attributes) and the manufacturing restriction database. The higher the selected level (Level 1 - Level 7) the more complex the part and the higher quality, which leads towards higher costs.

All the components of the GT code come together with the design attribute of the part to give tool design and manufacturing attributes which will be used to generate manufacturing operations, sequence, cost and time impact rating and manufacturing criticalities, all of which would be useful in the process of decision making. The developed GT code for the tool is illustrated in Table 3.

Table 3 Developed tool design and manufacturing code

\begin{tabular}{|c|c|c|c|}
\hline $\begin{array}{l}\text { Code } \\
\text { Position }\end{array}$ & $\begin{array}{l}\text { Code } \\
\text { Name }\end{array}$ & Feature & Description \\
\hline \multicolumn{4}{|c|}{ Primary code: Design attributes } \\
\hline 0 & $\mathrm{P}_{7}$ & Type of mould base & $\begin{array}{l}\text { The number signifies the type of mould base for } \\
\text { the tool for circular or rectangular applications. }\end{array}$ \\
\hline 1 & $\mathrm{P}_{8}$ & Mould classification & $\begin{array}{l}\text { The number signifies the type of mould based on } \\
\text { production phase for which mould is being } \\
\text { made. }\end{array}$ \\
\hline 2 & $\mathrm{P}_{9}$ & Type of mould & $\begin{array}{l}\text { It depends on the type of mould based on part } \\
\text { requirement. }\end{array}$ \\
\hline 3 & $\mathrm{P}_{10}$ & Number of cavities & $\begin{array}{l}\text { It depends on the number of cavities decided by } \\
\text { cycle time. }\end{array}$ \\
\hline 4 & $\mathrm{P}_{11}$ & Material & $\begin{array}{l}\text { It depends on the material used for cavities, } \\
\text { bases and runners and on corrosion resistance. }\end{array}$ \\
\hline 5 & $\mathrm{P}_{12}$ & $\mathrm{~L} / \mathrm{D}$ or $\mathrm{A} / \mathrm{B}$ and $\mathrm{A} / \mathrm{C}$ ratio & $\begin{array}{l}\text { It depends on whether the moulded part is } \\
\text { rotational or non-rotational. }\end{array}$ \\
\hline
\end{tabular}




\begin{tabular}{|c|c|c|c|}
\hline \begin{tabular}{|l|} 
Code \\
Position \\
\end{tabular} & $\begin{array}{l}\text { Code } \\
\text { Name }\end{array}$ & Feature & Description \\
\hline \multicolumn{4}{|c|}{ Secondary code: Manufacturing attributes } \\
\hline 6 & $\mathrm{P}_{13}$ & Mould parting line & $\begin{array}{l}\text { It depends on the part produced, i.e. the decision } \\
\text { for the mould parting is influenced by easy } \\
\text { product removal and where critical geometry } \\
\text { lies on the part. }\end{array}$ \\
\hline 7 & $\mathrm{P}_{14}$ & Mould ejection system & $\begin{array}{l}\text { It depends on the production efficiency and } \\
\text { product quality. }\end{array}$ \\
\hline 8 & $\mathrm{P}_{15}$ & Level of runners & $\begin{array}{l}\text { It depends on the number of cavities and the } \\
\text { location of gates. }\end{array}$ \\
\hline 9 & $\mathrm{P}_{16}$ & Mould cavity gating & $\begin{array}{l}\text { Gating greatly influenced by internal detail of } \\
\text { parts and number of cavities }\end{array}$ \\
\hline \multicolumn{4}{|c|}{ Supplementary code: Details of manufacturing attributes } \\
\hline A & $\mathrm{P}_{17}$ & Mould venting & $\begin{array}{l}\text { This is related to the raw material to be used and } \\
\text { the setting of a venting value for that material, } \\
\text { i.e. machining requirement related to the } \\
\text { material }\end{array}$ \\
\hline B & $\mathrm{P}_{18}$ & Mould surface finish & $\begin{array}{l}\text { It depends on the surface finish desired from the } \\
\text { mould. }\end{array}$ \\
\hline $\mathrm{C}$ & $\mathrm{P}_{19}$ & Polishing & The outer periphery characteristic \\
\hline $\mathrm{D}$ & $\mathrm{P}_{20}$ & $\begin{array}{l}\text { Mould temperature } \\
\text { control }\end{array}$ & $\begin{array}{l}\text { It is based on the processed material, mould } \\
\text { weight and heat up time, quantity of the material } \\
\text { being processed, mould temperature drops and } \\
\text { flow conditions. A control unit is selected based } \\
\text { on these considerations. }\end{array}$ \\
\hline \multicolumn{4}{|c|}{ Costing code: Attributes of mould influencing costs } \\
\hline $\mathrm{X}$ & $\mathrm{P}_{21}$ & $\begin{array}{l}\text { Complexity of mould } \\
\text { structure }\end{array}$ & $\begin{array}{l}\text { The number signifies the structure of the mould } \\
\text { and its associated complexity for manufacturing }\end{array}$ \\
\hline Y & $\mathrm{P}_{22}$ & Product quality & $\begin{array}{l}\text { It depends on the desired quality of the required } \\
\text { product. }\end{array}$ \\
\hline $\mathrm{Z}$ & $\mathrm{P}_{23}$ & $\begin{array}{l}\text { Heat treatment } \\
\text { requirement }\end{array}$ & $\begin{array}{l}\text { It is based on the required characteristics of the } \\
\text { finished product }\end{array}$ \\
\hline
\end{tabular}

The values for the above presented coding system $\left(\mathrm{P}_{1}-\mathrm{P}_{23}\right)$ are derived from a table which may vary depending on requirements of the user and the company based on the design and manufacturing parameters of part and tool (die and mould). Hence, further details of coding have been developed by combining the codes of the part and the tool. Fig. 5 presents a complete description of all codes $\left(\mathrm{P}_{1}-\mathrm{P}_{23}\right)$. A scheme of detailed codes is presented in Table 4 . It is to be noted that for each of the codes $\left(\mathrm{P}_{1}-\mathrm{P}_{23}\right)$ the range of the number of descriptions (columns) may vary, hence a different maximum index (a to $\mathrm{w}$ ) is assigned to each row. 
Table 4 Selection of GT code descriptions

\begin{tabular}{|c|c|c|c|c|c|c|c|c|c|c|}
\hline \multirow{2}{*}{\multicolumn{3}{|c|}{ Code }} & \multicolumn{8}{|c|}{ Description } \\
\hline & & & 1 & 2 & 3 & 4 & 5 & 6 & $\ldots$ & $x$ \\
\hline \multirow{6}{*}{ 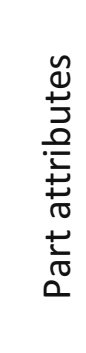 } & 0 & $P_{1}$ & $P_{1,1}$ & $P_{1,2}$ & $P_{1,3}$ & $P_{1,4}$ & $P_{1,5}$ & $P_{1,6}$ & ... & $P_{1, a}$ \\
\hline & 1 & $P_{2}$ & $P_{2,1}$ & $P_{2,2}$ & $P_{2,3}$ & $P_{2,4}$ & $P_{2,5}$ & $P_{2,6}$ & $\ldots$ & $P_{2, b}$ \\
\hline & 2 & $P_{3}$ & $P_{3,1}$ & $P_{3,2}$ & $P_{3,3}$ & $P_{3,4}$ & $P_{3,5}$ & $P_{3,6}$ & $\ldots$ & $P_{3, c}$ \\
\hline & 3 & $\mathrm{P}_{4}$ & $P_{4,1}$ & $P_{4,2}$ & $P_{4,3}$ & $P_{4,4}$ & $\mathrm{P}_{4,5}$ & $P_{4,6}$ & $\ldots$ & $P_{4, d}$ \\
\hline & 4 & $P_{5}$ & $P_{5,1}$ & $P_{5,2}$ & $P_{5,3}$ & $P_{5,4}$ & $P_{5,5}$ & $P_{5,6}$ & $\ldots$ & $P_{5, e}$ \\
\hline & 5 & $P_{6}$ & $P_{6,1}$ & $P_{6,2}$ & $P_{6,3}$ & $P_{6,4}$ & $P_{6,5}$ & $P_{6,6}$ & $\ldots$ & $P_{6, f}$ \\
\hline \multirow{7}{*}{ 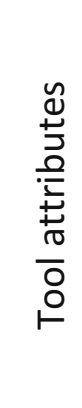 } & 0 & $P_{7}$ & $P_{7,1}$ & $P_{7,2}$ & $P_{7,3}$ & $P_{7,4}$ & $P_{7,5}$ & $P_{7,6}$ & $\ldots$ & $P_{7, g}$ \\
\hline & 1 & $P_{8}$ & $P_{8,1}$ & $P_{8,2}$ & $P_{8,3}$ & $P_{8,4}$ & $P_{8,5}$ & $P_{8,6}$ & $\ldots$ & $P_{8, h}$ \\
\hline & - & - & - & - & - & - & - & - & $\ldots$ & - \\
\hline & - & - & - & - & - & - & - & - & $\ldots$ & - \\
\hline & - & - & - & - & - & - & - & - & $\ldots$ & - \\
\hline & - & - & - & - & - & - & - & - & $\ldots$ & - \\
\hline & Z & $P_{23}$ & $P_{23,1}$ & $P_{23,2}$ & $P_{23,3}$ & $P_{23,4}$ & $P_{23,5}$ & $P_{23,6}$ & $\ldots$ & $P_{23, w}$ \\
\hline
\end{tabular}

Table 4 gives an idea of how to select values for $\mathrm{P}_{1}-\mathrm{P}_{23}$ from Fig. 5. For instance, depending on our design and manufacturing consideration, part code $\mathrm{P}_{4}$ has an attribute given in column 4 , hence code $\mathrm{P}_{4,4}$ is applicable and will be used as the $4^{\text {th }}$ digit of the code which would be the number of the column, which is 4 in this case. In this manner all the values from $\mathrm{P}_{1}-\mathrm{P}_{23}$ (a snippet example can be seen at the end of the paper) can be derived from the established table by the user or by an AFR system.

\subsection{Identification of manufacturing process}

The purpose of this part is to integrate the GT code developed for critical manufacturing operations and integrate it into a particular manufacturing sequence. This part of the paper will also include the operation details to ensure smooth manufacturing. Fig. 6 shows the step-wise process for the selection of appropriate manufacturing operations.

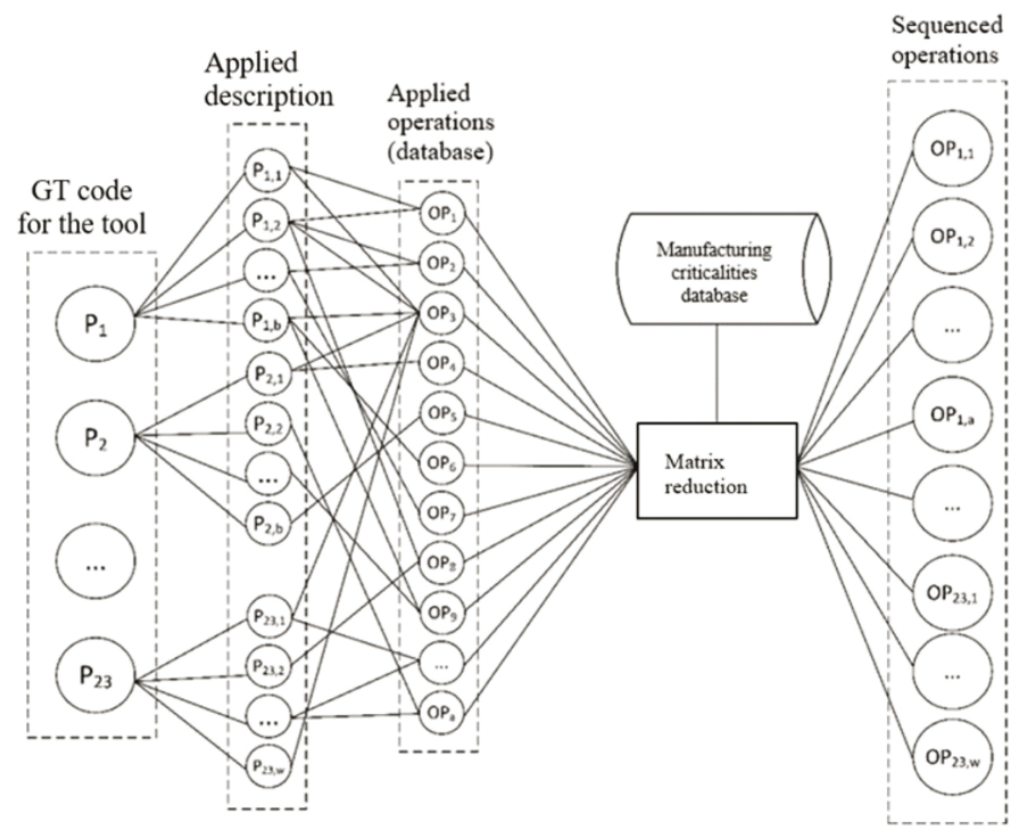

Fig. 6 Selection of manufacturing operations for tools 
The form code for the part corresponds to a certain description defining the restrictions in the manufacturing. The form code contains information about the part falling into the rotational or non-rotational category. The internal and external shape element may employ different operations such as plane, face and straddle milling operations respective of their geometric orientation. If the part is along an inclined angle, then the mould that is formed to produce the part may require form milling and profile milling operations. If it is stepped along with inclination, then the complexity of the part is increased. The presence of holes in the part may require cores in the die for injection moulding applications. Greater detail will account for increased complexity.

The form code for the tool accounts for primary design attributes of the mould and it has a relative effect on mould manufacturing. The number of cavities plays a crucial role in the manufacturing operation as in the case of a single cavity mould deep roughing can be carried out with a low depth-of-cut machining in finishing operations. The mould parting line which is non-flat, profiled or angled requires an extensive use of profile milling and angular milling. However, a flat parting line does not need extensive machining but only plane and side milling. The complex ejection system employs the use of EDM that essentially requires better mould finish. The presence of more cavities and more gates at the cavities may directly influence the choice of the runner level in the mould, which may cause an increase in machining operations.

Manufacturing restrictions are also included in the system which account for a certain preset value in the GT code, when a restriction is imposed. For example, if the manufacturer requires that the use of EDM be as low as possible, then certain limitations will be imposed on the GT code so that only these options may be selected. This in fact helps the manufacturer in selecting the manufacturing operations by taking cost and time into account and it also helps to plan during the procedure of the initial part selection.

A manufacturing criticalities database developed during the study includes a multitude of inputs based on the manufacturer's identified constituents and constraints. The prime identifiable aspects that have a direct impact on manufacturing are considered to be manufacturing operation parameters, operation element planning and sequencing, manufacturing resource identification and allocation, environmental impact and conditions, tool geometry, cutting fluids, energy saving aspects and optimum force applications by the tool during operations along relevant jig and fixture related information that may be used for performing the machining operation on the tool. An illustration of manufacturing criticalities databases is shown in Fig. 7.

The resulting process operations can be integrated in the cost and time impact factor rating system to produce a possible outcome of the process. It helps the manufacturer to decide what factors may influence these parameters and to tweak the

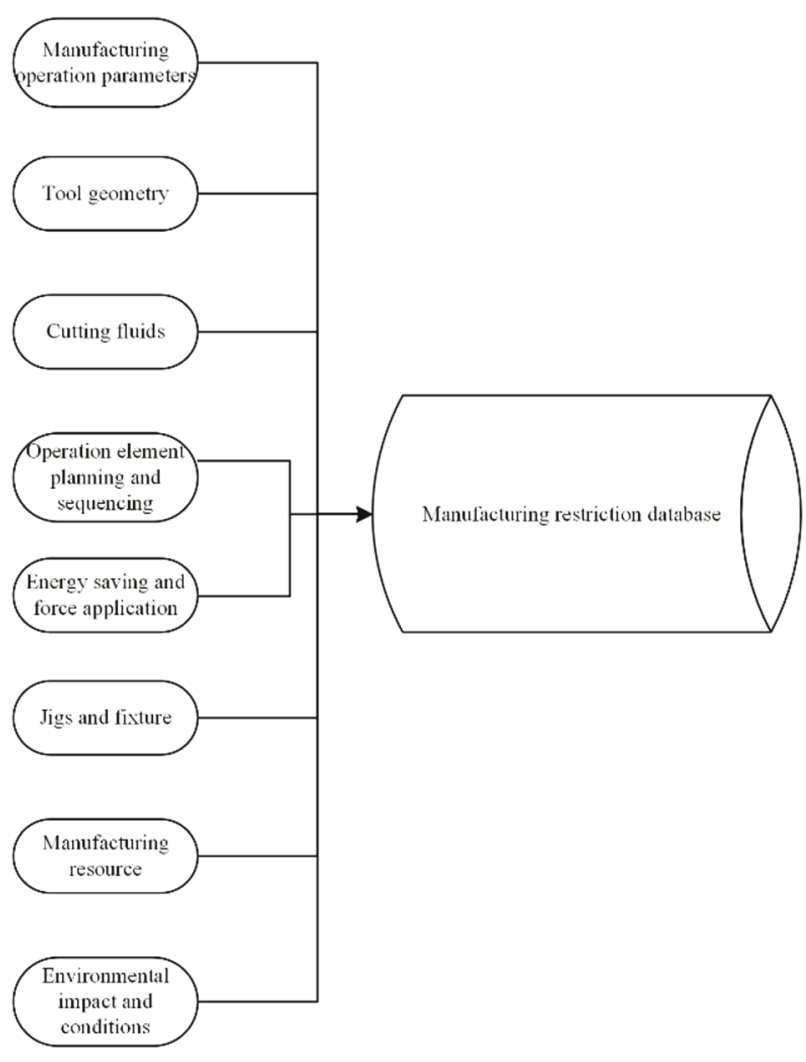

Fig. 7 Inputs for manufacturing criticalities database 
enables an optimum selection of process operations and their scheduling as well as a development of a good production plan.

Every GT code will correspond to a unique identifier which relates to a certain set of manufacturing criticalities which may be looked up in the database when that GT code is entered. These criticalities help the planner or manufacturer to converge all possible domains that may somehow affect the process. This kind of database in conjunction with the ES greatly reduces the reliance on industry experts and specialists in the planning of complex tool machining.

The established manufacturing database is concerned with manufacturing operation process parameters such as feed, speed and depth of cut to be considered for each specific machining operation. The established considerations refer to optimum outcome conditions for available manufacturing resources. There can be certain criticalities with respect to the impact which a machining process may have on the environment and also the effect of the environment on the machining operation. An environmental consideration may be flow of chips and its interaction with operators and how a control of such a case may be included in the database.

Tool geometry is also quite important for an efficient machining operation along with cutting fluids (which include recommendation for possible lubricants and coolants). The database includes recommendations for tool geometry for the manufacturing of a tool for good production cases, such as what type and angles/dimensions to take into the account and what should they be set at for the best possible outcome. Since the tool is a solid part, a necessary design practice is to have some jig and fixture related information for machining, such as where to best position locators and clamps, which will depend on its dimensions. Also, the database includes incentives for effective energy utilization, such as process parameter and force application by the tool. The associated collective database is an extremely large data set where the GT code value infers the said recommendations stored in the database, which the manufacturer should follow for each manufacturing operation to achieve the optimum and effective outcome.

\subsection{Sequencing the operations}

A system is set up to determine the sequences of operations by the matrix reduction method based on GT code. The method takes manufacturing operations frequently applied in the die and mould design and manufacture into account. A necessary precondition is set up for each respective process. The matrix reduction method connects manufacturing operations to their preconditions. The first element of the manufacturing process is the element that has no preconditions. The activity that follows usually depends on the completion of the previous activity (precondition is the previous activity). The process is repeated until all activities are carried out (a snippet example can be seen at end of the paper). The process is very helpful in sequencing the operations and determining the number of variants. The matrix reduction method can be combined with the Gantt chart to result in a feasible schedule for a possible optimized process plan for the manufacture of die and mould applications. The matrix reduction method can be carried out using an algorithm on a computer or manually.

\subsection{Determination of time and cost impact factor}

The maximum percent average method is used in this study to determine an impact factor rating for the manufacturing process. The research is built on the previous research on enhancing injection moulding quotation accuracy [15]. A GT code corresponds to a specific value for unit and its relative importance on manufacturing cost and time impact factor. The maximum percent average method is used to assign an average value to each individual number in the group technology (GT) coding system based on relative importance in terms of perceived cost and time impact factor of the said number. 
As discussed above, a number of operations $\left(\mathrm{OP}_{1}\right.$ to $\left.\mathrm{OP}_{\mathrm{x}}\right)$ are selected by applying the matrix reduction technique for each GT code $\left(\mathrm{P}_{1}-\mathrm{P}_{23}\right)$ related to the part and tool attributes. To determine the impact factor of time and cost, two data tables for the impact factors are generated for each impact factor. Impact factor is assigned to each position in the operation element for each unit of the GT code. The impact factor values are based on intuition (can be different for different manufacturers) that makes the essence of ESs. To determine the impact factors of cost and time, impact factor $\left(\mathrm{IF}_{\mathrm{x}, \mathrm{y}, \mathrm{z}}\right)$ is allocated to each operation element based on experience corresponding to a GT code. Here, the operation element is defined as the operation that will be performed to manufacture the tool identified when the GT code is entered by either the AFR system or the user. However, not limited to one GT code only, the machines can be re-called for other scenarios. The IF values are followed by an identifier such as $\mathrm{IF}_{1,2,2}$ that corresponds to $\mathrm{P}_{1}$ GT code ( $\mathrm{x}=$ first digit of subscript), operations element 2 ( $\mathrm{y}=$ second digit of subscript) and GT code description 2 ( $\mathrm{z}=$ third digit of subscript). A generalized impact factor table for time and cost is shown as Table 5.

Table 5 Generalized impact factor for time and cost

\begin{tabular}{|c|c|c|c|c|c|c|c|c|c|c|c|c|c|c|c|c|}
\hline & \multicolumn{4}{|c|}{$\mathrm{OP}_{1}$} & \multicolumn{4}{|c|}{$\mathrm{OP}_{2}$} & \multicolumn{4}{|c|}{ OP... } & \multicolumn{4}{|c|}{$\mathrm{OP}_{\mathrm{w}}$} \\
\hline & 1 & 2 & $\ldots$ & $a$ & 1 & 2 & $\ldots$ & $b$ & $\ldots$ & $\ldots$ & $\ldots$ & $\ldots$ & 1 & 2 & $\ldots$ & $w$ \\
\hline$P_{1}$ & $\mathrm{IF}_{1,1,1}$ & $\mathrm{IF}_{1,1,2}$ & $\mathrm{IF}_{1,1, .}$ & $\mathrm{IF}_{1,1, \mathrm{a}}$ & $\mathrm{IF}_{1,2,1}$ & $\mathrm{IF}_{1,2,2}$ & $\mathrm{IF}_{1,2, \mathrm{.}}$ & $\mathrm{IF}_{1,2, \mathrm{~b}}$ & $\ldots$ & $\ldots$ & $\ldots$ & $\ldots$ & $\mathrm{IF}_{1, x, 1}$ & $\mathrm{IF}_{1, x, 2}$ & $\mathrm{IF}_{1, \mathrm{x}, \mathrm{.}}$ & $\mathrm{IF}_{1, \mathrm{x}, \mathrm{b}}$ \\
\hline$P_{2}$ & $\mathrm{IF}_{2,1,1}$ & $\mathrm{IF}_{2,1,2}$ & $\mathrm{IF}_{2,1, .}$ & $\mathrm{IF}_{2,1, \mathrm{a}}$ & $\mathrm{IF}_{2,2,1}$ & $\mathrm{IF}_{2,2,2}$ & $\mathrm{IF}_{2,2, \mathrm{.}}$ & $\mathrm{IF}_{2,2, \mathrm{~b}}$ & $\ldots$ & $\ldots$ & $\ldots$ & $\ldots$ & $\mathrm{IF}_{2, \mathrm{x}, 1}$ & $\mathrm{IF}_{2, \mathrm{x}, 2}$ & $\mathrm{IF}_{2, \mathrm{x}, \mathrm{.}}$ & $\mathrm{IF}_{2, \mathrm{x}, \mathrm{b}}$ \\
\hline$P_{3}$ & $\mathrm{IF}_{3,1,1}$ & $\mathrm{IF}_{3,1,2}$ & $\mathrm{IF}_{3,1, .}$ & $\mathrm{IF}_{3,1, \mathrm{a}}$ & $\mathrm{IF}_{3,2,1}$ & $\mathrm{IF}_{3,2,2}$ & $\mathrm{IF}_{3,2, .}$ & $\mathrm{IF}_{3,2, \mathrm{~b}}$ & $\ldots$ & $\ldots$ & $\ldots$ & $\ldots$ & $\mathrm{IF}_{3, \mathrm{x}, 1}$ & $\mathrm{IF}_{3, x, 2}$ & $\mathrm{IF}_{3, \mathrm{x}, .}$ & $\mathrm{IF}_{3, \mathrm{x}, \mathrm{b}}$ \\
\hline$\ldots$ & $\mathrm{IF}_{\cdot, 1,1}$ & $\mathrm{IF}_{., 1,2}$ & $\mathrm{IF}_{., 1, .}$ & $\mathrm{IF}_{., 1, \mathrm{a}}$ & $\mathrm{IF}_{\cdot, 2,1}$ & $\mathrm{IF}_{., 2,2}$ & $\mathrm{IF}_{., 2, .}$ & $\mathrm{IF}_{., 2, \mathrm{~b}}$ & $\ldots$ & $\ldots$ & $\ldots$ & $\ldots$ & $\mathrm{IF}_{\cdot, x, 1}$ & $\mathrm{IF}_{., \mathrm{x}, 2}$ & $\mathrm{IF}_{., \mathrm{x}, \mathrm{.}}$ & $\mathrm{IF}_{., \mathrm{x}, \mathrm{b}}$ \\
\hline$P_{23}$ & $\mathrm{IF}_{23,1,1}$ & $\mathrm{IF}_{23,1,2}$ & $\mathrm{IF}_{23,1, .}$ & $\mathrm{IF}_{23,1, \mathrm{a}}$ & $\mathrm{IF}_{23,2,1}$ & $\mathrm{IF}_{23,2,2}$ & $I_{23,2, .}$ & $\mathrm{IF}_{23,2, \mathrm{~b}}$ & $\ldots$ & $\ldots$ & $\ldots$ & $\ldots$ & $\mathrm{IF}_{23, x, 1}$ & $\mathrm{IF}_{23, x, 2}$ & $\mathrm{IF}_{23, \mathrm{x}}$ & $\mathrm{IF}_{23, \mathrm{x}, \mathrm{b}}$ \\
\hline
\end{tabular}

A maximum of each range corresponding to each operation element from each GT code unit is extracted. For example, in GT code $\mathrm{P}_{1}$, for operation $\mathrm{OP}_{1}$, has operation elements 1 to a, hence a maximum impact factor would be searched within the limits 1 to a (row-wise). Within the same GT code, for operation element $\mathrm{OP}_{2}$, the maximum impact factor would be searched within its own range ( 1 to b). The sum of maxima for each GT code would be taken as follows:

$$
X_{x}=\sum_{x=1}^{a, b, \ldots, w} \max \left(I F_{x, y, z}\right) \text {. }
$$

where ' $x$ ' is the index for the GT code starting from 1 to $23\left(\mathrm{P}_{1}\right.$ to $\left.\mathrm{P}_{23}\right)$. The sum of all added maximum impact factors of the GT codes are given by

$$
A=\sum_{x=1}^{23} X_{x}
$$

Now, the summation of actual impact factors for the process element will be taken. Actual impact factors for the process element that correspond to the GT code are those which are selected based on the part form code and the manufacturing code. Here, the sum of impact factors within each GT code can be given by;

$$
Y_{x}=\sum_{x=1}^{a, b, \ldots, w} I F_{x, y, z}
$$

The sum of all added impact factors of the GT codes is given by: 


$$
B=\sum_{x=1}^{23} Y_{x}
$$

A percent impact factor is derived by dividing the resulting value (B) by the final summed maximum value (A) to signify a comparative importance of the part in time and cost scenarios. Mathematically it is given by

$$
\text { Impact factor for time or cost }=\frac{B}{A} \times 100 \text {. }
$$

A range is set that corresponds to low, medium and high impact factor based on the impact percent range, i.e., $0-100$. This range helps to distinguish the part for a particular GT code thereby completely connecting a geometric part to the manufacturing cost and time. The impact rating can be viewed on the impact meters developed for both cost and time for fast decisionmaking support and the study of the variability of the GT code on final impact rating in the ES. The meters developed (shown in Fig. 8) are as follows for decision support which can be modified depending on the requirement.

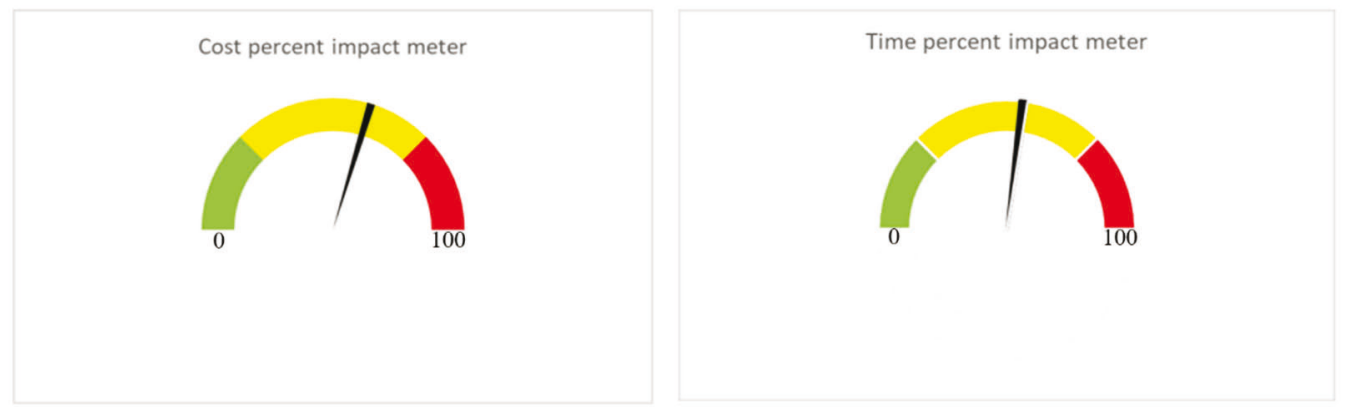

Fig. 8 Impact factor meters for decision support

Fig. 8 shows the developed meters based on the discussed algorithm, each with three specific regions, namely, green, yellow and red. These regions define the level of decisionmaking feasibility with green going towards the higher end and the lower end being towards the red region. The pointer (in black) moves in reference to the time and cost impact rating. The more the pointer is inclined towards the red region the more critical the part and tool become in terms of the cost and time scenario. Decisions have to be taken depending on the respective position of the pointer. Table 6 presents quantitative ranges of the meter region and recommended decisions. These can be set up to suit the requirements of the industry.

Table 6 Description of cost/time impact meter

\begin{tabular}{|l|l|l|}
\hline Recommendation & Percentage & Region colour \\
\hline Most feasible region & $0-25$ & Green \\
\hline Moderately feasible region & $25-50$ & Yellow \\
\hline Infeasible region & $50-100$ & Red \\
\hline
\end{tabular}

\subsection{Manufacturing restrictions analysis on decision}

Manufacturing restrictions are also applied to cater for the need of robustness in the process planning. At this stage, process planner can provide certain restrictions to re-process the process planning to reduce the time and cost impact factors if these are higher than the requirement. In the case of time, the effect of the restriction becomes more extended as the selection of a normal condition for time will result in a direct implication on complexity and quality. However, if fast production is desired, only low or medium quality and complexity 
parts can be produced. In this way, time will result in a restricted selection for complexity and quality, which will in turn restrict the selection of the GT code components. In the defined condition, the study here also addresses the problem of imposing restrictions and their effect on the entire process planning of the mould technology. The developed algorithm can be considered to give a decision based on sensitivity of the imposed restrictions. The restrictions can be applied using the data provided in Table 1. Fig. 9 shows the manufacturing restrictions and their conditions.

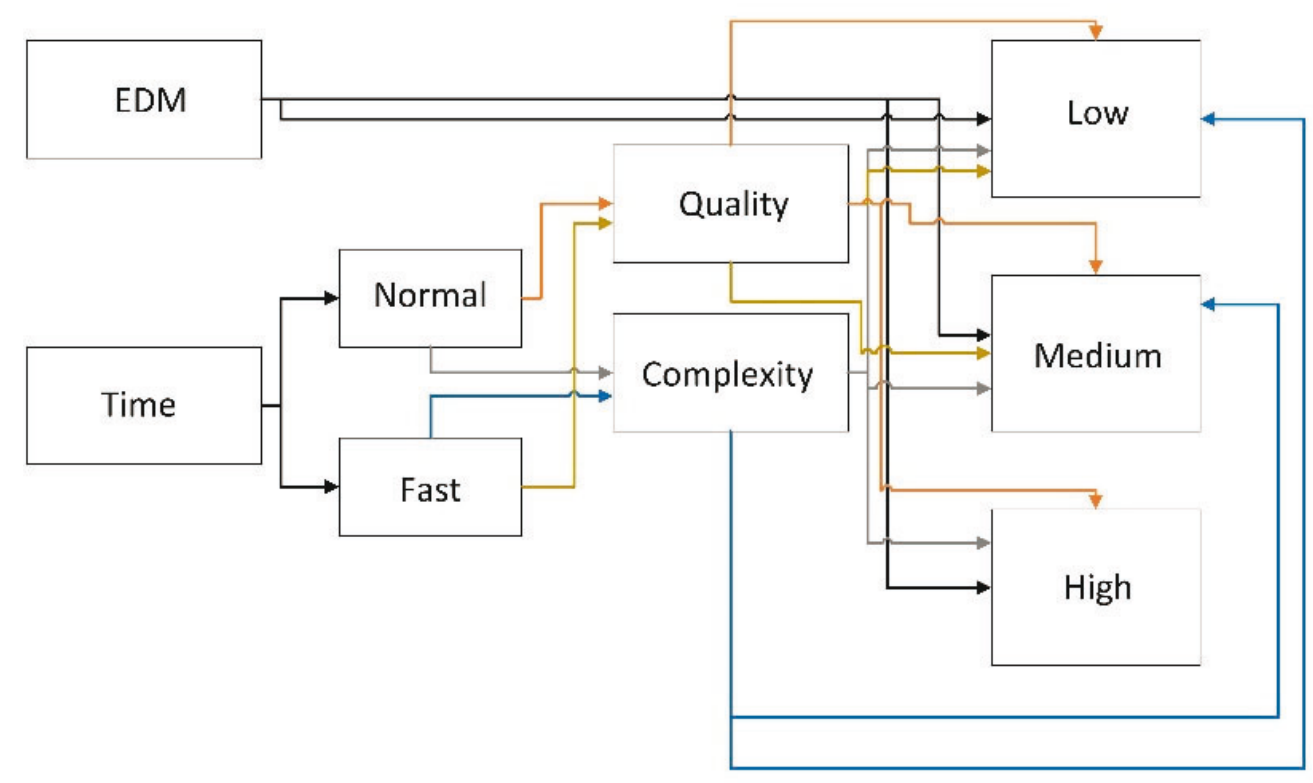

Fig. 9 Manufacturing restrictions with implications on EDM usage and time connected with quality and complexity in process planning cycle

\section{Application}

To illustrate how the ES works, a bracket is taken as reference part. Manufacturing restrictions are imposed to study the effect on the result. A GT code is derived based on the design and manufacturing attributes of the part and the tool. The resultant GT code generated manufacturing processes, criticalities and the sequence that needs to be followed, along with time and cost impact rating.

The step-wise execution of the MTES algorithm provides a better illustration of how the ESs works.

Step 1: The ABS-based bracket part is decided to be manufactured by plastic injection moulding using dies and moulds. Fig. 10 shows the geometry of the bracket.

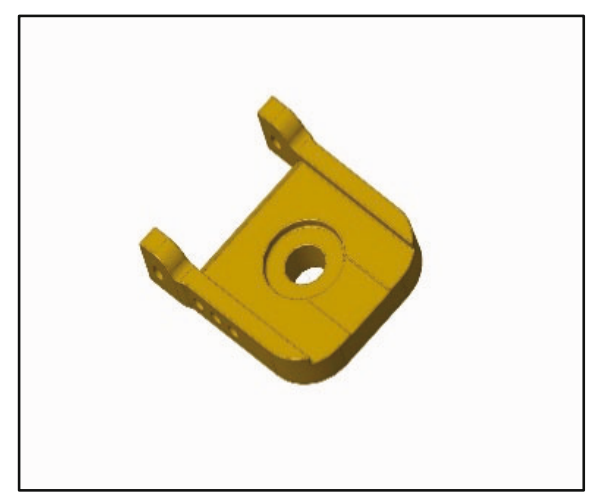

Fig. 10 ABS-based bracket 
Step 2: The manufacturing criticalities are defined as low usage of EDM, low complexity, low quality and normal production time (refer to Table 1 for details).

Step 3: Using the Opitz code, the group technology (GT) code for the part is selected based on the geometry of the bracket, which is illustrated in Table 7 . The form code of the part is 644253 .

Table 7 Form code of the part

\begin{tabular}{|l|l|}
\hline Code & Description \\
\hline 6 & $\mathrm{~A} / \mathrm{B}<3 \quad \mathrm{~A} / \mathrm{C}>4$ \\
\hline 4 & Functional groove \\
\hline 4 & Functional groove \\
\hline 2 & Surface plane and/or curved in one direction, external \\
\hline 5 & Axial and/or radial and/or other direction \\
\hline 3 & Level 3 \\
\hline
\end{tabular}

Step 4: The form code of the tool is selected using the developed system for the given geometry of the bracket. Table 8 presents the selected code of the tool, its manufacturing and detailed codes and their description.

Table 8 Form code for the tool

\begin{tabular}{|c|c|c|c|c|c|}
\hline \multicolumn{2}{|l|}{ Code } & Description & \multicolumn{2}{|c|}{ Code } & Description \\
\hline \multirow{6}{*}{$\begin{array}{l}0 \\
8 \\
0 \\
\Xi \\
0 \\
0\end{array}$} & 1 & Rectangular cross-section & \multirow{6}{*}{ 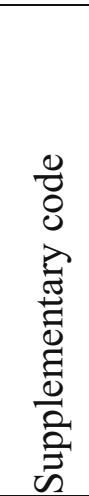 } & 1 & Flat (parting line) \\
\hline & 1 & Prototype mould & & \multirow{4}{*}{ 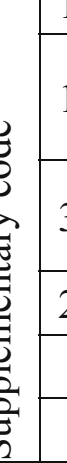 } & $\begin{array}{l}\text { Ejection pin on sliders } \\
2 \text { sliders per part for ejection }\end{array}$ \\
\hline & 1 & Two- plate mould & & & $\begin{array}{l}\text { Level } 3 \text { (three level runner } \\
\text { system) }\end{array}$ \\
\hline & 1 & 2 (number of cavities) & & & Tab gating \\
\hline & 3 & 2711 (tool steel material) & & & \\
\hline & 6 & $\mathrm{~A} / \mathrm{B}<3 \quad \mathrm{~A} / \mathrm{C}>4$ & & & \\
\hline \multirow{4}{*}{ 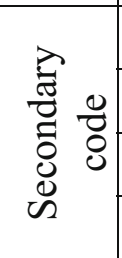 } & 3 & Acrylic $(0.0381-0.0508 \mathrm{~mm})$ & \multirow{4}{*}{$\begin{array}{l}0 \\
0 \\
0 \\
0 \\
0 \\
0 \\
0 \\
0\end{array}$} & 3 & Level 3 (low complex) \\
\hline & 3 & $\mathrm{~A} 3 / \mathrm{B} 1$ & & 3 & Level 3 (low quality) \\
\hline & 4 & 5000-10000 rpm final polishing & & 3 & Level 3 (moderate heat treatment) \\
\hline & 1 & Standard guideline & & & \\
\hline
\end{tabular}

Step 5: When entering the GT code for planning consideration is asked from the user regarding the time aspect required for the process. In this study, the following processes and preconditions were taken into account and the matrix reduction method was employed (refer to Table 9). 
Table 9 Sequence of operations considered in the study

\begin{tabular}{|l|l|l|l|l|l|}
\hline S.No. & $\begin{array}{l}\text { Manufacturing } \\
\text { operation }\end{array}$ & $\begin{array}{l}\text { Precedence } \\
\text { constraint }\end{array}$ & S.No. & $\begin{array}{l}\text { Manufacturing } \\
\text { operation }\end{array}$ & $\begin{array}{l}\text { Precedence } \\
\text { constraint }\end{array}$ \\
\hline 1 & Plain milling & 16 & 11 & Die sinking & 8 \\
\hline 2 & Face milling & 1 & 12 & Boring & 14 \\
\hline 3 & Side milling & 2 & 13 & Reaming & 12 \\
\hline 4 & Straddle milling & 1 & 14 & Drilling & 18 \\
\hline 5 & Angular milling & $2,6,4$ & 15 & EDM & 11 \\
\hline 6 & Gang milling & 1 & 16 & Grinding & 0 \\
\hline 7 & Form milling & $3,5,6$ & 17 & Polishing & 19 \\
\hline 8 & Profile milling & 8 & 18 & Superfinishing & 15 \\
\hline 9 & Helical milling & 0,8 & 19 & Heat treatment & 20 \\
\hline 10 & Thread milling & 13 & 20 & Coating & 10 \\
\hline
\end{tabular}

Step 6: The matrix reduction shows three sequences which the manufacturer may follow towards part completion. Sequences were associated with time dependence to link the sequencing with the time dependence scenario in the GT code. Table 10 presents three possible combinations of manufacturing operations.

Table 10 Possible sequence of operations derived from matrix reduction method

\begin{tabular}{|l|l|l|l|}
\hline No. & Sequence 1 & Sequence 2 & Sequence 3 \\
\hline 1 & Grinding & Grinding & Grinding \\
\hline 2 & Plane milling & Gang milling & Straddle milling \\
\hline 3 & Face milling & Angular milling & Angular milling \\
\hline 4 & Side milling & Form milling & Form milling \\
\hline 5 & Angular milling & Profile milling & Profile milling \\
\hline 6 & Form milling & Helical milling & Helical milling \\
\hline 7 & Profile milling & Die sinking & Die sinking \\
\hline 8 & Helical milling & EDM & EDM \\
\hline 9 & Die sinking & Drilling & Drilling \\
\hline 10 & EDM & Boring & Boring \\
\hline 11 & Drilling & Reaming & Reaming \\
\hline 12 & Boring & Superfinishing & Superfinishing \\
\hline 13 & Reaming & Thread milling & Thread milling \\
\hline 14 & Superfinishing & Coating & Coating \\
\hline 15 & Thread milling & Heat treatment & Heat treatment \\
\hline 16 & Coating & Polishing & Polishing \\
\hline 17 & Heat treatment & & \\
\hline 18 & Polishing & & \\
\hline
\end{tabular}

Step 7: The sequence number is generated based on the input restrictions and the GT code derived by the matrix reduction algorithm. The cost and time impact factors are generated using the established formulae. Figs. 11 and 12 show the determined impact factors of time and cost. The cost impact rating in this case is 58.38 and the time rating is 53.17. So, the part would incur a moderate cost and resource (machine and time) requirement. 


\begin{tabular}{|l|r|l|r|}
\hline \multicolumn{2}{|c|}{ Cost meter } & \multicolumn{2}{|c|}{ Pointer } \\
\hline Start & 0 & Value(Cost) & 58.38150289 \\
\hline Initial & 25 & Pointer & 139.6184971 \\
\hline Middle & 50 & End & \\
\hline End & 25 & & \\
\hline Max & 100 & \multicolumn{2}{|c|}{ Pointer } \\
\hline \multicolumn{2}{|r|}{ Time meter } & \multicolumn{2}{|c|}{2} \\
\hline Start & 0 & Value(Time) & 53.17185698 \\
\hline Initial & 25 & Pointer & 144.828143 \\
\hline Middle & 50 & End & \\
\hline End & 25 & & \\
\hline Max & 100 & & \\
\hline
\end{tabular}

\begin{tabular}{|c|c|}
\hline $\begin{array}{c}\text { Sequence } \\
\text { number }\end{array}$ & 1 \\
\hline
\end{tabular}

Fig. 11 Generated impact factors of time and cost (taken from ES)

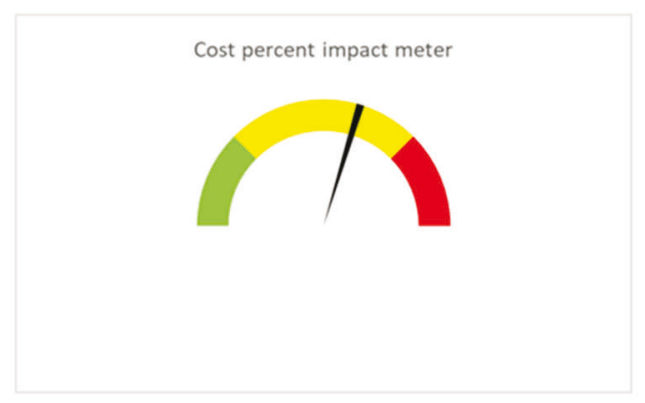

Time percent impact meter

Fig. 12 Time and cost impact meters for tool (generated from ES)

The cost and time impact meters help in decision making (red region denotes high time and cost requirement). Fig. 13 shows the mould developed using the CAD software.

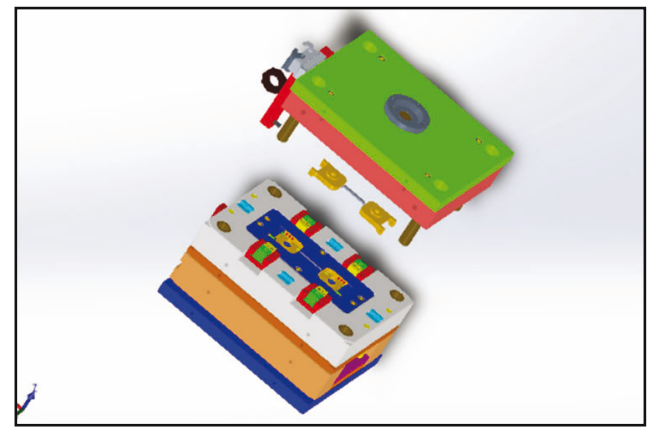

Fig. 13 Model mould for bracket

The details of the manufacturing processes that will be employed to produce the tool for the bracket along with their criticalities are presented in Table 9 as output of the ES. The table only mentions the processes that have criticalities associated with the manufacturing processes.

Table 9 Manufacturing criticalities for bracket derived from algorithm

\begin{tabular}{|l|l|l|}
\hline S.No. & $\begin{array}{l}\text { Manufacturing } \\
\text { processes }\end{array}$ & Criticalities \\
\hline 1 & Plain milling & $\begin{array}{l}\text { Employ minute plane milling for roughing purposes. } \\
\text { Roughing then finishing followed by end mill operation for } \\
\text { slot mill. } \\
\text { Roughing on the plane side only. }\end{array}$ \\
\hline
\end{tabular}




\begin{tabular}{|c|c|c|}
\hline S.No. & $\begin{array}{l}\text { Manufacturing } \\
\text { processes }\end{array}$ & Criticalities \\
\hline & & $\begin{array}{l}\text { Customized as per requirement. } \\
\text { Machining }(\mathrm{M} / \mathrm{c} \text { ) level increases (Decrease depth of cut (d.o.c) } \\
\text { and increase speed). } \\
\text { Roughing followed by finishing by end mill. } \\
\text { Employ minute plane milling for roughing purposes. } \\
\text { Plain milling decreases with an increase in complexity. } \\
\text { Roughing lower with reduced (statistical process control } \\
\text { (SPC) tolerance. }\end{array}$ \\
\hline 2 & Face milling & $\begin{array}{l}\text { Employ minute face milling for finishing purposes. } \\
\text { End mill operation for slot mill. } \\
\text { Finishing on the plane side only . } \\
\text { Customized as per requirement. } \\
\text { M/c level increases (Decrease d.o.c and increase speed). } \\
\text { Finishing operation low d.o.c. } \\
\text { Employ minute face milling for finishing purposes. } \\
\text { Face milling increases with an increase in complexity. }\end{array}$ \\
\hline 3 & Side milling & $\begin{array}{l}\text { Employ minute side milling for roughing/finishing purposes. } \\
\text { End mill for slot milling. } \\
\text { Employed for finishing process. } \\
\text { M/c level increases (Decrease depth of cut (d.o.c) and increase } \\
\text { speed). } \\
\text { Side milling for feature. } \\
\text { Employ minute side milling for roughing/finishing purposes. } \\
\text { With increasing levels of complexity machining costs } \\
\text { increase. }\end{array}$ \\
\hline 4 & Straddle milling & $\begin{array}{l}\text { Slotting with equidistant spacer straddle mill. } \\
\text { Depends on whether equidistant parallel surfaces are to be } \\
\text { machined. } \\
\text { High complexity increased straddle milling. }\end{array}$ \\
\hline 5 & Angular milling & Angular v-notch - double angle cutter. \\
\hline 6 & Gang milling & $\begin{array}{l}\text { Slotting with equidistant spacer end mills. } \\
\text { High complexity increased gang milling. }\end{array}$ \\
\hline 7 & Form milling & Convex/concave/corner rounding milling cutting geometry. \\
\hline 8 & Profile milling & $\begin{array}{l}\text { Surface plane and/or curved in one direction, external by end } \\
\text { mill. } \\
\text { Profile mill by end mill cutter. } \\
\text { With increasing levels of complexity machining cost } \\
\text { increases. }\end{array}$ \\
\hline 9 & Helical milling & $\begin{array}{l}\text { Groove made by specially formed milling or double-edged } \\
\text { milling cutters. }\end{array}$ \\
\hline 10 & Die sinking & $\begin{array}{l}\text { Low die sinking use for finishing operation only. } \\
\text { Die sinking decrease with increasing cavities. }\end{array}$ \\
\hline
\end{tabular}




\begin{tabular}{|l|l|l|}
\hline S.No. & $\begin{array}{l}\text { Manufacturing } \\
\text { processes }\end{array}$ & Criticalities \\
\hline 11 & Boring & $\begin{array}{l}\text { Boring tool smaller than required diameter. Look for line } \\
\text { boring or back boring. }\end{array}$ \\
\hline 12 & Reaming & $\begin{array}{l}\text { Reaming tool smaller than required diameter. Look for } \\
\text { adjustable/straight/rose/shell/tapered/combination reamer. }\end{array}$ \\
\hline 14 & EDM & $\begin{array}{l}\text { Drilling tool smaller than required diameter. Look for } \\
\text { spot/centre/deep hole/micro/vibrational drilling. }\end{array}$ \\
\hline 15 & $\begin{array}{l}\text { Low EDM use for finishing operation only. } \\
\text { Look for considerations (number of parts, surface finish, } \\
\text { cooling, cycle time, etc.) for hardened (S-7, H-13, 420 } \\
\text { stainless steel) and pre-hardened tool steels that are composed } \\
\text { of P-20 and mod pre-hardened stainless steel. } \\
\text { EDM process with parameters derived from material standard. } \\
\text { See standard for material. } \\
\text { EDM process depends on the gating point desired on the final } \\
\text { part and the cavity position as well as level of gating. }\end{array}$ \\
\hline 16 & Heat treatment & $\begin{array}{l}\text { Minute grinding for deburring. } \\
\text { Before roughing for deburring operation only. } \\
\text { Minute grinding for deburring. }\end{array}$ \\
\hline
\end{tabular}

\section{Conclusion and directions for future research}

The study combines design attributes, manufacturing attributes, imposed implications, and manufacturing restrictions for mould manufacturing. A coding system is presented that links manufacturing processes, some descriptions and sequence of operations with their resultant time and cost impact. Therefore, the study provides a platform for cross-examination and elaboration at the whole production level to develop a suitable process plan based on the optimization algorithm. Time and cost analyses are also performed for the process plan, which provide an insight into the feasibility of the processes so that the plan can be optimized in line with the customer demands.

The result of the study is a well optimized scenario for faster process planning of die and mould manufacture for moulding applications. The study presents the significance of a combined approach to process planning. Rather than the traditional approach where the planning activity happens after going through each respective information hub, this study presents an idea of making a collective ES that includes all that information. This helps in making faster and more accurate decisions.

The work provides a system called MTES (Mould Tool ES) that contains feature identification and classification by group technology codes coupled with manufacturer-oriented restrictions. The system integrates the code developed to include tool and part design and manufacturing attributes. This system then proceeds with manufacturing operation identification, operation sequencing and time and cost impact rating. Manufacturing process criticalities are also integrated to enable a feasible decision.

The developed system is adaptable and has a capability of expansion to suit the manufacturer's needs. For instance, the GT code for part and tool can be expanded or modified to suit the offered functionalities. However, further work needs to be done to make the system more compatible with evolving mould requirements, e.g., when very intricate profiling is 
necessary or when further detailed defining of a feature is required. A sub-level system for each individual feature needs to be defined. Furthermore, with the changing horizon in manufacturing the need for digitalization of information and using the information to direct a behaviour, e.g. in self-configuration facilities or multi-agent based systems, is becoming more significant. So, further research can be done in such cases.

\section{REFERENCES}

[1] Lee, K., Principles of CAD/CAM/CAE Systems, Addison Wesley Longman, Boston, USA. 1999. ISBN 0-201-38036-6.

[2] Pratihar, D.K., ESs in manufacturing processes using soft computing (2015) Int J Adv Manuf Technol, 81: 887. https://doi.org/10.1007/s00170-015-7285-X.

[3] De Lacalle, L., Lamikiz, A., Salgado, M., Herranz, S. and Rivero, A. (2002). Process planning for reliable high-speed machining of moulds. International Journal of Production Research, 40(12): 2789-2809. https://doi.org/10.1080/00207540210140068

[4] Meng Lim, E. and Menq, C. (1997). Integrated planning for precision machining of complex surfaces. Part 1: Cutting-path and feedrate optimization. International Journal of Machine Tools and Manufacture, 37(1): 61-75. https://doi.org/10.1016/0890-6955(95)00109-3

[5] Wang, L. and Chen, Z. (2014). A new CAD/CAM/CAE integration approach to predicting tool deflection of end mills. The International Journal of Advanced Manufacturing Technology, 72(9-12): 1677-1686. https://doi.org/10.1007/s00170-014-5760-4

[6] Krajnik, P. and Kopač, J. (2004). Modern machining of die and mould tools. Journal of Materials Processing Technology, 157-158: 543-552. https://doi.org/10.1016/j.jmatprotec.2004.07.146

[7] Le, V., Paris, H. and Mandil, G. (2017). Process planning for combined additive and subtractive manufacturing technologies in a remanufacturing context. Journal of Manufacturing Systems, 44: 243 254. https://doi.org/10.1016/j.jmsy.2017.06.003

[8] Altan, T., Lilly, B., Yen, Y. and Altan, T. (2001). Manufacturing of Dies and Moulds. CIRP Annals, 50(2): 404-422. https://doi.org/10.1016/S0007-8506(07)62988-6

[9] Martínez, K., Toso, E. and Morabito, R. (2016). Production planning in the moulded pulp packaging industry. Computers \& Industrial Engineering, 98: 554-566. https://doi.org/10.1016/j.cie.2016.05.024

[10] Wu, B. and Wang, J. (2009). A neuro-fuzzy approach to generating mould/die polishing sequences. Journal of Materials Processing Technology, 209(7): 3241-3250. https://doi.org/10.1016/j.jmatprotec.2008.07.031

[11] Cakir, M., Irfan, O. and Cavdar, K. (2005). An ES approach for die and mould making operations. Robotics and Computer-Integrated Manufacturing, 21(2): 175-183. https://doi.org/10.1016/j.rcim.2004.07.015

[12] Lim, J., Rho, H. and Cho, K. (1994). A knowledge-based process planning system for injection mould. Computers \& Industrial Engineering, 27(1-4): 95-98. https://doi.org/10.1016/0360-8352(94)90245-3

[13] Nakao, M., Yamada, S., Kuwabara, M., Otubo, M. and Hatamura, Y. (2002). Decision-based process design for shortening the lead time for mould design and production. CIRP Annals, 51(1): 127-130. https://doi.org/10.1016/S0007-8506(07)61482-6

[14] Wongwiwat, A., Bohez, E. and Pisuchpen, R. (2013). Production scheduling for injection moulding manufacture using Petri Net model. Assembly Automation, 33(3): 282-293. https://doi.org/10.1108/AA12-2013-063

[15] Mikó, Balázs \& Boór, Ferenc. (2007). Enhancing of injection mould quotation accuracy. Proc. Estonian Acad. Sci. Eng. 13: 94-104.

[16] Denkena, B. and Nemeti, A. (2013). Stock Market Related Pricing Mechanisms for the Tool and Mould Manufacturing Industry. Procedia CIRP, 12: 414-419. https://doi.org/10.1016/j.procir.2013.09.071

[17] Vázquez, E., Amaro, A., Ciurana, J. and Rodríguez, C. (2015). Process planning considerations for micromilling of mould cavities used in ultrasonic moulding technology. Precision Engineering, 39: 252260. https://doi.org/10.1016/j.precisioneng.2014.07.001

[18] Kumar, S. P. L. (2017). State of The Art-Intense Review on Artificial Intelligence Systems Application in Process Planning and Manufacturing. Engineering Applications of Artificial Intelligence, 65: 294-329. https://doi.org/10.1016/j.engappai.2017.08.005 
[19] Chen, C., Wang, Y., Ou, H., He, Y. and Tang, X. (2014). A review on remanufacture of dies and moulds. Journal of Cleaner Production, 64: 13-23. https://doi.org/10.1016/j.jclepro.2013.09.014

[20] Basinger, K.L., Keough, C.B., Webster, C.E. et al. Development of a modular computer-aided process planning (CAPP) system for additive-subtractive hybrid manufacturing of pockets, holes, and flat surfaces. Int J Adv Manuf Technol (2018) 96: 2407. https://doi.org/10.1007/s00170-018-1674-x.

[21] Al-wswasi, M., Ivanov, A. \& Makatsoris, H. A survey on smart automated computer-aided process planning (ACAPP) techniques. Int J Adv Manuf Technol (2018) 97: 809. https://doi.org/10.1007/s00170018-1966-1

[22] Behandish M, Nelaturi S, Kleer J, Automated process planning for hybrid manufacturing, ComputerAided Design Vol. 102, September 2018, Pages 115-127. https://doi.org/10.1016/j.cad.2018.04.022

[23] M. S. A. Karim and C. Tai Tiong, "Development of a Simple and Affordable Computer Aided Process Planning (CAPP)," 2019 Advances in Science and Engineering Technology International Conferences (ASET), Dubai, United Arab Emirates, 2019, pp. 1-4. https://doi.org/10.1109/ICASET.2019.8714443

[24] Alexander Houtzeel, "Integrating CAD/CAM Through Group Technology," paper presented at the American Production and Inventory Control Society operations management workshop, Michigan State University, July 26-28, 1982; and Inyong Ham, "Introduction to Group Technology," Society of Manufacturing Engineers, technical report MMR 76-03, 1976.

[25] Acomould.com. (2018). Mould Design For Manufacturing (DFM) Report. [online] Available at: http://www.acomould.com/mould-dfm-report.html [Accessed 14 Jun. 2018].

[26] Dme.net. 2021. American Standard Mould Bases [online] Available at: https://www.dme.net/wpcontent/uploads/PDFCatalogs/MoldBases\&PlatesCatalog2020.pdf [Accessed 19 June 2021].

Submitted: $\quad 12.02 .2021$

Accepted: $\quad$ 13.9.2021
Hamood Ur Rehman*, PhD Researcher Advanced Manufacturing Technology

Research Group, University of Nottingham, Nottingham, United Kingdom.

Ferenc Boór, Research Associate Department of Manufacturing Science and Engineering, Budapest University of Technology and Economics, Budapest, Hungary.

Muhammad Wasif, Assistant Professor Syed Amir Iqbal, Professor Department of Industrial and Manufacturing Engineering (IMD), NED

University of Engineering and

Technology, Karachi, Pakistan.

*Corresponding author:

Hamood.Rehman@nottingham.ac.uk 
H. Ur Rehman, F. Boór,

M. Wasif, S.A. Iqbal
A Novel Method for Process Planning for Die and Mould Manufacturing Using Expert System Approach

\section{Support material}

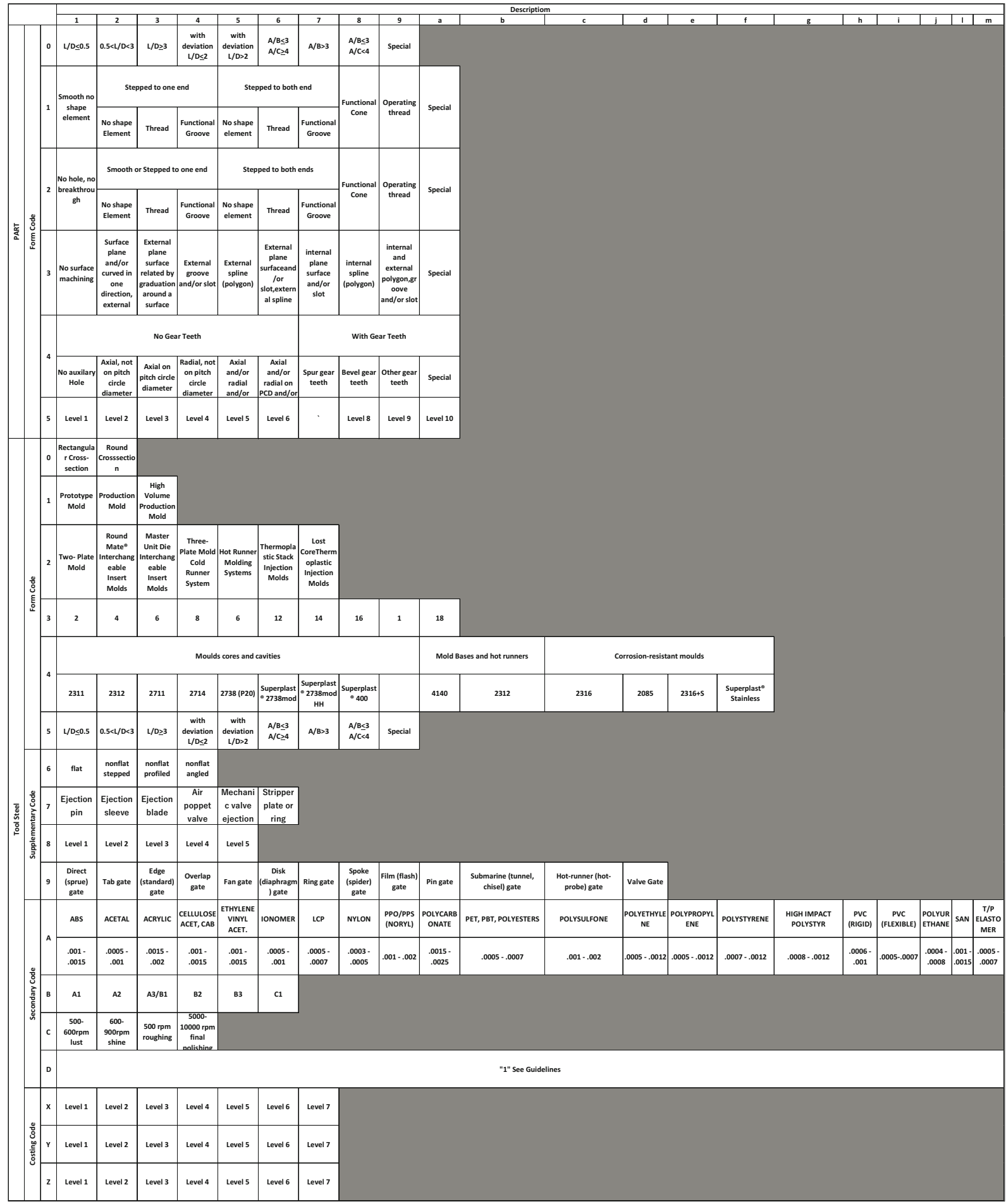

Developed GT code snippet taken from MTES for tool attributes, manufacturing and its details 